$12 \S$ To whom correspondence should be addressed:

13 Prof. Philip Demokritou,

14 Associate Professor, Department of Environmental Health, Harvard T.H. Chan School of Public

15 Health, 677 Huntington Avenue, Boston, MA 02115, USA

16 pdemokri@hsph.harvard.edu

17 Tel: 617-432-3481

18

19

21

22

23

\author{
Christa Watson-Wright, Dilpreet Singh, Philip Demokritou ${ }^{\S}$
} T.H. Chan School of Public Health, 677 Huntington Avenue, Boston, MA 02115, USA

\section{of Nano-Enabled Thermoplastics \\ Toxicological Implications of Released Particulate Matter during Thermal Decomposition}

Christa Watson-Wright, Dilpreet Singh, Philip Demokritou

Center for Nanotechnology and Nanotoxicology, Department of Environmental Health, Harvard 
Nano-enabled thermoplastics are part of the growing market of nano-enabled products (NEPs) that have vast utility in several industries and consumer goods. The use and disposal of NEPs at their end of life has raised concerns about the potential release of constituent engineered nanomaterials (ENMs) during thermal decomposition and their impact on environmental health and safety. To investigate this issue, industrially relevant nano-enabled thermoplastics including polyurethane, polycarbonate, and polypropylene containing carbon nanotubes $(0.1$ and $3 \% \mathrm{w} / \mathrm{v}$, respectively), polyethylene containing nanoscale iron oxide $(5 \% \mathrm{w} / \mathrm{v})$, and ethylene vinyl acetate containing nanoscale titania $(2$ and $5 \% \mathrm{w} / \mathrm{v})$ along with their pure thermoplastic matrices were thermally decomposed using the recently developed lab based Integrated Exposure Generation System (INEXS). The life cycle released particulate matter (called LCPM) was monitored using real time instrumentation, size fractionated, sampled, extracted and prepared for toxicological analysis using primary small airway epithelial cells to assess potential toxicological effects. Various cellular assays were used to assess reactive oxygen species and total glutathione as measurements of oxidative stress along with mitochondrial function, cellular viability, and DNA damage. By comparing toxicological profiles of LCPM released from polymer only (control) with nano-enabled LCPM, potential nanofiller effects due to the use of ENMs were determined. 


\section{Introduction}

In the last fifty years, the polymer industry has flooded the marketplace with numerous thermoplastic products for a variety of applications. In fact, thermoplastics have become common components in various household goods, building materials, food packaging/preparation, and various consumer products. Lately, the inclusion of engineered nanomaterials (ENMs) into polymer formulations has generated nanocomposites that have enhanced functionality in comparison to their predecessors. Nano-enabled thermoplastics or nanocomposites can contain nanofillers such as silica nanoparticles (Stojanović et al., 2013), clays (Fang et al., 2008), metal oxides (Perkgoz et al., 2011), carbon fibers (Al-Saleh et al., 2013) and carbon nanotubes (Sahoo et al., 2010) enabling extensive mechanical and electrical properties. Although, ENMs afford many useful properties, certain ENMs can cause adverse health effects such as cytotoxicity (DeLoid et al., 2016; DeLoid et al., 2014; Pirela et al., 2013; Pirela et al., 2014a), genotoxicity (Watson et al., 2013), epigenetic changes (Lu et al., 2016a; Lu et al., 2016b), and lung inflammation upon exposure (Borm et al., 2006; Konduru et al., 2014; Pirela, et al., 2013; Pirela et al., 2016). With this in mind, considerable concern over the hazards that may ensue due to the release of ENMs during consumer use and disposal of nano-enabled thermoplastics has created efforts to understand potential exposures across the life cycle of nanoenabled products (Bouillard et al., 2013; Grassian et al., 2016; Pirela et al., 2014b; Sisler et al., 2014; Wohlleben et al., 2011; Wohlleben and Neubauer, 2016).

At their end of use, a large portion of nanocomposites, approximately 20,000 metric tons per year, will be introduced into the waste stream to be recycled, placed in landfills or incinerated (Keller and Lazareva, 2014). Various polymers have been associated with leaching of various toxins over time due to thermodecomposition or dissolution (Teuten et al., 2009). For example, thermoplastics such as polyurethane are synthesized from isocyanates, which are low molecular weight compounds that can be released during thermal decomposition of polyurethane and are known for inducing occupational asthma after inhalation (Gui et al., 2014). In vitro studies have shown isocyanates, released during thermal decomposition, can elicit augmentation of mitochondrial reactive oxygen species production, depletion of antioxidant defense enzymes, and elevated pro-inflammatory cytokine response in endothelial cells (Panwar et al., 2013). Polyethylene is an ethylene polymer used in cosmetics as an abrasive, adhesive, binder or 
bulking agent in the food and medical industries. Upon thermodecomposition, polyethylene has been found to emit high amounts of polycyclic aromatic hydrocarbons, which can be carcinogenic (Wang et al., 2003). Polycarbonate (PC) is a widely used polymer in the food industry, however incineration of polycarbonate has been known to release bisphenol-A (BPA) (Kitahara et al., 2010). Clearly, polymers possess inherent properties that may cause serious health effects during thermal decomposition and subsequent exposure, which may be intensified if ENMs are incorporated. However, very little is known about potential synergistic effects upon ENM release during thermal degradation of NEPs.

A variety of inorganic and organic ENMs are utilized by different industries as nanofillers in various thermoplastics. One of the most widely used ENM in the polymer industry is carbon nanotubes (CNTs). Carbon nanotubes endow thermoplastics with enhanced properties such as resistance to scratch and wear (Giraldo et al., 2008), elevated tensile strength and Young's modulus (Wang et al., 2008) and conductivity (Huang and Terentjev, 2010). The features of CNTs have been utilized in numerous sectors such as the automotive, aerospace, and sporting goods industries. Although CNTs provide numerous benefits, exposure to these ENMs in their pristine form has been associated with genotoxicity (Vales et al., 2016), tumor formation (Wang et al., 2011), and fibrosis due to inhalation (Fatkhutdinova et al., 2016). Adverse cellular responses to CNT exposures have been linked to the high aspect ratio characteristic and residual metals used in the synthesis of these particular ENMs (Donaldson et al., 2010; Mihalchik et al., 2015; Tsuruoka et al., 2015). Likewise, metal oxide ENMs such as iron oxide $\left(\mathrm{Fe}_{2} \mathrm{O}_{3}\right)$ and titanium $\left(\mathrm{TiO}_{2}\right)$ are currently utilized in a number of nano-enabled products to enhance optical (Li et al., 2010), antimicrobial (Palza, 2015), and magnetic (Novakova et al., 2003) properties among others. These same properties could elicit adverse effects in biological systems by inhibiting cellular and physiological processes (Larsen et al., 2016; Lu, et al., 2016a; Lu, et al., 2016b). Whether ENMs used in various NEPS can be released across the life cycle and pose human health hazards remains unclear due to the limited number of studies focusing on comprehensive life cycle environmental health and safety implications of NEPs.

Currently, there are limited studies addressing the hazards associated with thermal decomposition of NEPs and associated released particulate matter (called LCPM). The lack of comprehensive end of life cycle studies is mainly due to inadequate standardized methods across 
113 the continuum of LCPM exposure generation-characterization and subsequent toxicological 114 assessment. Recently, the Integrated Exposure Generation System (INEXS) was developed in our lab for systematically and reproducibly investigating the thermal decomposition of NEPs under controlled conditions (Sotiriou et al., 2015). INEXS allows for a detailed in-situ and exsitu physicochemical, morphological and toxicological characterization of the byproducts, namely, the released aerosol (life cycle particulate matter, LCPM) and the remaining residual ash (see Methods for more details on INEXS platform).

With this platform, we recently investigated the thermal decomposition of industriallyrelevant thermoplastic polymer NEPs, employing both organic and inorganic nanofillers (Sotiriou et al., 2016; Singh et al., in revision). In summary, it was shown that there was nanofiller-related release into the air especially for the inorganic metal oxide nanofillers but not so for carbonaceous nanofillers (such as CNTs and organic pigments). Most of the inorganic and carbonaceous nanofillers remained in the residual ash, except at high temperature (such as 800 ${ }^{\circ} \mathrm{C}$ ) when the carbonaceous nanofillers were fully combusted. The released aerosol size and particle number concentration were primarily mediated by the nanofiller type and loading. However, the elemental and organic carbon analysis (EC/OC) of the released aerosol seemed to be primarily governed by the host polymer matrix as it was composed of $99 \mathrm{wt} \%$ or more organic carbon irrespective of nanofiller presence and loading. In another study by Verjerano and coworkers, the influence of raw ENMs during the combustion of "bulk" waste was investigated. In that study, an association between the thermal decomposition of waste spiked with various loadings of added pristine nanomaterials and the formation of combustion byproducts such as polycyclic aromatic hydrocarbons and chlorinated furans was found (Vejerano et al., 2014). Within that study, only small amounts of ENMs (0.023-180 $\mathrm{mg} \mathrm{g}^{-1}$ of nanomaterial) were found to be released in the aerosol. It is worth noting that the referenced study did not investigate the release of ENMs from nano-enabled products but rather spiked "waste" with pristine ENMS such as nickel oxide, fullerenes $\left(\mathrm{C}_{60}\right), \mathrm{Ce}_{2} \mathrm{O}_{3}, \mathrm{TiO}_{2}, \mathrm{Fe}_{2} \mathrm{O}_{3}$, quantum dots, and silver before combustion; however, evidence of nanomaterial mediated production of hazardous byproducts during thermo-decomposition was demonstrated.

While the kinetics of nano-release scenarios from thermal decomposition of nano enabled thermoplastics has been clearly made in our recently published papers, toxicological properties 
of LCPM have not been reported yet and are needed for risk assessment purposes. The primary goal of this companion study is to determine the toxicological profile of the released LCPM for the same industrially relevant nano-enabled thermoplastics studied in our previous published papers. More importantly, this study aims to assess the effect of nanofiller type and loading, thermoplastic matrix and their effect on bioactivity with emphasis to elucidate effects due to the incorporation of engineered nanomaterials or a "nano-filler effect". A number of hypotheses were evaluated: 1) The presence of nanofiller in the thermoplastic material will influence the toxicological profile of LCPM exposures. 2) Nanofiller loading will impact dose-response relationships; 3) The host polymer matrix will influence toxicological profiles of LCPM exposures. To determine the toxicological properties of inhaled LCPM, biological endpoints such as metabolic activity, mitochondrial function, oxidative stress, and DNA damage were assessed using small airway epithelial cells.

\section{Materials and Methods}

\subsection{Synthesis and characterization of thermoplastic polymer NEPs}

The industrially-relevant nano-enabled thermoplastics or nanocomposites used in this investigation were extensively characterized as described in great detail in our recently published papers. It is worth noting that polymer NEPs with no nanofillers (host matrices) were synthesized and used as a control in the various thermal decomposition investigations. The pristine ENMs (nanofillers) were also included in our toxicological assessments as comparator materials. A summary of the various nano-enabled thermoplastics investigated is presented in Table 1.

\subsection{Generation and sampling of LCPM for the toxicological assessment using the} Integrated Exposure Generation System (INEXS)

The INEXS platform (Supplemental Figure 1) was used here to perform a systematic investigation of the thermal decomposition of NEPs under controlled combustion conditions and to generate the required LCPM particles for toxicological evaluation (Sotiriou et al., 2015). In summary, the platform enables thermal decomposition of an NEP, post-release treatment of the released aerosol through one of the three possible routes, and the detailed physicochemical, morphological and toxicological characterization of the byproducts, both in situ and ex situ. 
172 Briefly, a specified amount of the NEP (typically, $100 \mathrm{mg}$ ) is placed in a quartz crucible in the

173 tube furnace and heated to a final temperature of $800^{\circ} \mathrm{C}$ over 40 mins. The released aerosol is 174 then directed to one of the three possible post-release treatment scenarios. Route 1 is the 'no175 treatment' scenario whereby the released aerosol is monitored and characterized as-is. In Route

1762 , the released aerosol undergoes treatment through a thermal denuder where the aerosol is 177 heated to a temperature of $300^{\circ} \mathrm{C}$ to volatilize the semi-volatile organic compounds (sVOCs), 178 which are then stripped off by an activated carbon section. The purpose of removing sVOCs 179 from the released aerosol is to understand how the presence of sVOCs would impact the 180 181 toxicology of released LCPM. Route 3 includes additional heat treatment of the released aerosol at a high temperature $\left(800^{\circ} \mathrm{C}\right)$ for a minimum of $5 \mathrm{~s}$ of residence time, which is a requirement in commercial waste incinerators (Clarke et al., 1991). This treatment scenario enables a simulation of what would happen to the released LCPM upon further thermal processing. After undergoing one of the three possible post-release treatment scenarios, the aerosol is monitored for its size, concentration and gaseous composition using a variety of real-time instrumentation. Furthermore, the released aerosol is sampled and size-fractionated and collected in the Harvard Compact Cascade Impactor (CCI) (Demokritou et al., 2004), which can then be extracted and analyzed ex-situ as described in great detail by Pal et. al (Pal et al., 2015b) and used for off-line chemical characterization and in-vitro cellular studies (see below for more details). The released aerosol may also be directed to an inhalation chamber for in vivo toxicological characterization 191 studies.

\subsection{Thermal Decomposition Scenario}

193

In this study, all NEPs were investigated at one thermal decomposition scenario, corresponding to final thermal decomposition temperature, $\mathrm{Td}=800^{\circ} \mathrm{C}$. The heating rate of the furnace corresponding to this final temperature was $19.4{ }^{\circ} \mathrm{C} / \mathrm{min}$ based on $40 \mathrm{mins}$ of ramping time from ambient $\left(25^{\circ} \mathrm{C}\right)$ to the final temperature. High-Efficiency Particulate Air (HEPA) filtered ambient air was supplied at $5 \mathrm{~L} / \mathrm{min}$ through the furnace during the entire thermal decomposition to support the oxygen requirement for incineration, maintaining the combustion atmosphere at ambient $\mathrm{N}_{2}: \mathrm{O}_{2}$ level. The released aerosol was passed through Route 1 (no additional thermal treatment). Route 1 was used for this study because the goal was to understand the nanofiller effects on total LCPM toxicity. Thus, the thermal denuder (Route 2, removal of sVOCs) and the 
extended heat treatment (Route 3) were not evaluated in this study. Except for PC-based nanocomposites, $100 \mathrm{mg}$ of each material was used for thermal decomposition. The amount used for PC-CNT was $35 \mathrm{mg}$, because higher amounts resulted in excessive particle generation and blockage of the Teflon filter (used as a substrate for particle sampling), causing a reduced flow of ambient air into the furnace, thus changing the combustion conditions.

\subsection{Sampling and size-fractionation of released LCPM}

The released aerosol was size-fractionated using the Harvard CCI (Demokritou, et al., 2004). A flow of $30 \mathrm{~L} / \mathrm{min}$ was used through the impactor to achieve the fractionation into three sizefractions, namely, $\mathrm{PM}_{0.1}, \mathrm{PM}_{0.1-2.5}$, and $\mathrm{PM}_{>2.5}$. Polyurethane foam (PUF) substrates were used for collection of particles in the $\mathrm{PM}_{0.1-2.5}$, and $\mathrm{PM}_{>2.5}$ size fractions, whereas $\mathrm{PM}_{0.1}$ particles were collected on either Teflon filters (Teflo Membrane, $47 \mathrm{~mm}$ diameter, $2 \mu \mathrm{m}$ pore, Pall Corporation, Port Washington, NY) or quartz filters (Tissuquartz, $47 \mathrm{~mm}$ diameter, Pall Corporation, Port Washington, NY) depending on the required ex-situ analysis. All substrates and filters were chemically cleaned to remove any background contamination of trace metals and organics prior to particle sampling using a previously described protocol (Bello et al., 2013). In this study only the $\mathrm{PM}_{0.1}$ size fraction was used in the toxicological assessment.

\subsection{Physicochemical and morphological characterization of released LCPM}

The released gases and aerosols from the thermal decomposition of thermoplastics were extensively characterized both in situ and ex situ using state-of-the-art instrumentation and analytical techniques as described in our recently published companion papers (Sotiriou et al, Singh et al, in submission). In summary, elemental and organic carbon contents (EC-OC) of the $\mathrm{PM}_{0.1}$ size fraction of the released aerosol were determined by gas chromatography/mass spectrometry (GC-MS) using a previously standardized protocol (Schauer et al., 2003). Elemental analyses of the released aerosol $\left(\mathrm{PM}_{0.1}\right)$ was performed by magnetic sector field inductively coupled plasma mass spectrometry (SF-ICPMS) using a published protocol (Herner et al., 2006). Scanning electron microscopy (SEM, Zeiss Supra 55VP Field Emission Scanning Electron Microscope, Jena, Germany) was used to characterize the morphology of the released aerosol $\left(\mathrm{PM}_{0.1}\right)$ samples. 


\subsection{LCPM Extraction and Dispersion}

For proper toxicological assessment, collected LCPM was extracted using the SEDD (sampling, extraction, dispersion, and dosimetry) methodology previously developed by the authors (Pal, et al., 2015b). The SEDD methodology consists of five steps: Briefly, in step one generated aerosols or LCPM are sampled using state of the art instrumentation (SMPS and APS) and size fractionated using the Harvard CCI, which uses collection media such as Teflon filters. Step 2 of the SEDD methodology involves the extraction of collected LCPM from Teflon filters through sonication and solvent washing of collection media enabling minimal alteration of physicochemical properties of the LCPM. Briefly, collection media were submerged in a beaker containing $75 \%$ ethanol solution and sonicated for 4 min delivering $466 \mathrm{~J} / \mathrm{ml}$ sonication energy. The ethanol portion of the suspension was removed by evaporation and dilution in deionized water using a Rotovap system. In step 4, the recovered LCPM were dispersed using a dispersion protocol described by Cohen et al. and Pal et al, where the critical sonication energy was delivered to the LCPM suspensions to reduce agglomerate size and create stable colloidal suspensions (Cohen et al., 2013; Pal, et al., 2015b). Dispersed stock solutions in $\mathrm{DI}_{2} \mathrm{O}$ were diluted to desired concentrations (see Table 3) in small airway basal media (SABM) (Lonza) and vortexed for 30 seconds. Step 5 involves using colloidal characterization parameters such as the volume weighted hydrodynamic diameter and the effective density of the formed agglomerates in SABM media to input into the Harvard In Vitro dosimetric platform which is further described below.

\subsection{LCPM Colloidal Characterization}

LCPM suspensions in distilled water and SABM media were characterized for various particle and biologic media parameters by dynamic light scattering (DLS), which provided hydrodynamic diameter $\left(\mathrm{d}_{\mathrm{H}}\right)$, zeta potential, conductance, and $\mathrm{pH}$ determinations in particle liquid suspensions. The effective density of the formed agglomerates was measured using the volumetric centrifugation method (VCM) (DeLoid, et al., 2014). The volume weighted hydrodynamic diameter and the effective density parameters were used to determine dosimetric considerations. For LCPM colloids that are buoyant (effective density of formed agglomerates is less than that of culture medium), the modified VCM method as described in detail by Watson et al. was used (Watson et al., 2016). Endotoxin levels in LCPM samples were measured using the 
EndoZyme ${ }^{\circledR}$ recombinant factor $\mathrm{C}(\mathrm{rFC})$ assay (Hyglos, Germany) according to manufacturer's instructions.

\subsection{In vitro dosimetric considerations}

The recently developed, integrated Harvard In Vitro dosimetric platform was used to convert administered LCPM doses to delivered cell doses as a function of exposure time (Cohen et al., 2014b; DeLoid et al., 2015). This method consists of two highly integrated steps: 1) LCPM dispersion preparation and characterization (described above) (Cohen, et al., 2013; Cohen et al., 2014a); and 2) use of advanced fate and transport numerical models to estimate the settling of formed agglomerates as a function of exposure time. The recently developed at Harvard Distorted Grid (DG) model was utilized (DeLoid, et al., 2015) to calculate numerically the fraction of administered particles deposited on the small airway epithelial cell surface as a function of time, $\mathrm{f}_{\mathrm{D}}(\mathrm{t})$, for all LCPM suspensions. The volume weighted agglomerate hydrodynamic diameter, $\mathrm{d}_{\mathrm{H}}$, as measured by DLS, and the effective density of ENM agglomerates suspended in cell culture media, as measured by the Harvard volumetric centrifugation method (DeLoid, et al., 2014), were used as inputs to the numerical fate and transport model to calculate the concentrations at the bottom of well, fraction deposited, and the mass per surface area. Effort was made to match delivered doses across various LCPM by adjusting or using higher administered LCPM concentrations.

\subsection{Cell Culture and Exposure}

As inhalation exposures may be a potential concern for workers within the waste industry and for individuals during accidental fires in communities, we evaluated the cellular responses to LCPM using small airway epithelial cells. Normal small airway epithelial cells (SAEC) were purchased from Lonza and were cultured in small airway epithelial basal media (SABM) supplemented with (Lonza) supplemented with bovine pituitary extract (BPE), hydrocortisone, human epidermal growth factor (hEGF), epinephrine, transferrin, insulin, retinoic acid, triiodothyronine, gentamicin, amphotericin-B (GA-1000). SAEC were incubated in a humidified atmosphere of $37^{\circ} \mathrm{C} / 5 \% \mathrm{CO}_{2}$ until exposure to LCPM. Exposures to LCPM with an significantly lower effective density $\left(\leq 0.9 \mathrm{~g} / \mathrm{cm}^{3}\right)$ as compared to the cell culture media density $\left(1.011 \mathrm{~g} / \mathrm{cm}^{3}\right)$, were evaluated using the inverted cell culture (ICC) platform as previously described by the authors (Watson, et 
al., 2016). A low effective density results in buoyancy, in which case the suspended particles never settle on the bottom of the cell culture well, but accumulate at the top of the well over time. The ICC platform allows cells to be cultured in an inverted position throughout the duration of LCPM exposure to enable deposition and cellular interaction with buoyant LCPM such as PP and PP-CNT. For LCPM with effective density greater than $0.9 \mathrm{~g} / \mathrm{cm}^{3}$, conventional methods (standard 96 well plates) during exposure were used.

\subsection{Cell Viability Assays}

Metabolic activity was measured after LCPM exposures using CellTiter 96 Aqueous One Solution (MTS) (Promega, Madison, WI) assays. Briefly, cells (600 cells/well) were seeded in 96-well plates (Corning Inc., New York, NY) and were maintained until 70-80\% confluency. Fresh media was added to cells $(50 \mu 1)$ and $50 \mu$ of LCPM diluted in SABM at various concentrations (See Table 3) and incubated for $24 \mathrm{~h}$. After exposure, control and exposed cells were washed twice with 1x phosphate buffered saline (PBS). SABM containing MTS reagent was added for 1 hour and read at $490 \mathrm{~nm}$ using a microplate reader (SpectraMax M5, Molecular Devices, Sunnyvale, CA). Media, reference controls (raw nanofillers) and LCPM only controls were evaluated to ensure reagent integrity. Each assay was performed in triplicate.

\subsection{Mitochondrial membrane potential}

The TMRE (tetramethylrhodamine, ethyl ester) (Abcam) assay was used to determine the effects of LCPM on mitochondrial membrane potential. TMRE is a positively charged permeable dye that accumulates in active negatively charged mitochondria. If mitochondria are damaged or depolarized, the TMRE dye will not accumulate within the cell, reducing the detected signal. After LCPM exposure and removal, cell monolayers were washed three times with 1x PBS and emission spectra $(575 \mathrm{~nm})$ was obtained using a fluorescent microplate reader (SpectraMax M5, Molecular Devices, Sunnyvale, CA) at an excitation of $549 \mathrm{~nm}$. Each assay was performed in triplicate.

\subsection{Oxidative stress/reactive oxygen species (ROS) detection}

It is well known that many nanomaterials produce reactive oxygen species that can lead to deleterious effects in cells. Using the CellROX® Green ROS Detection Assay (Invitrogen), we 
assessed the ability of combustion-derived LCPM to generate reactive oxygen species in SAEC. Cells were exposed to LCPM for $24 \mathrm{~h}$. Following aspiration of suspensions and two washes with 1x PBS, CellROX Green diluted in complete media $(5 \mu \mathrm{M})$ was added to cells for 30 minutes at $37^{\circ} \mathrm{C}$. Fluorescent measurements were then performed using a fluorescent plate reader (Molecular Devices). Total glutathione levels were measured using the GSH-Glo assay according to manufacturer's instructions (Promega).

\subsection{CometChip-single stranded DNA damage assessments}

The recently developed high-throughput screening platform the CometChip was used to evaluate the DNA damage potential of LCPM exposures (Sotiriou et al., 2014; Watson, et al., 2013). The CometChip platform was prepared as described previously (Sotiriou, et al., 2014; Watson, et al., 2013). LCPM that induced cellular viability reductions greater than $50 \%$ were not assessed for DNA damage as excessive cytotoxicity can influence genotoxicity evaluations. CometChip imaging and quantitative analysis was performed using an automated fluorescent microscope (Leica) and MATLAB (The MathWorks, Natick, MA) software, respectively.

\subsection{Statistical Analysis}

LCPM evaluations were conducted three times and results were expressed as means \pm standard deviation for at least three biological experiments. Statistical differences between the means were determined by performing one-way analysis of variance (ANOVA) using Prism version 5 (GraphPad Software, La Jolla, California) and a treatment/nanofiller effect with p-value of $\leq$ 0.05 was considered significant.

\section{Results}

\subsection{Released LCPM characterization}

LCPM characterization is presented in great detail in our recent companion publications (Sotiriou et al, Singh et al, in revision). In summary:

\section{LCPM aerosol concentration and physico-chemical composition:}

The maximum released aerosol concentration during thermal decomposition is in the order of $10^{8}$ particles $/ \mathrm{cm}^{3}$ in the nano-regime (Supplemental Figure 2A). The average mobility size at the peak concentration ranges from $\sim 100-200 \mathrm{~nm}$ (Supplemental Figure 2B). There was no 
nanofiller release detected for the carbonaceous nanofillers (CNTs) at all investigated temperature conditions. However, nanofiller-related release was detected, although at low concentrations $(<0.03 \mathrm{wt} \%)$ for inorganic nanofillers such as $\mathrm{Fe}_{2} \mathrm{O}_{3}$ and $\mathrm{TiO}_{2}$. The nanofillerrelated release was found to be dependent on nanofiller-loading and enhanced at the lower decomposition temperature. The total VOC concentration in the combustion off-gas was found to be between $\sim 100-150$ ppm.

The released aerosol is primarily composed of greater than 99 wt\% organic compounds irrespective of the final temperature or the type and loading of nanofiller, as evident from the EC-OC results (Supplemental Table 1). The host polymer matrix appears to govern the overall EC-OC chemistry of the released aerosol (Supplemental Figure 3). Electron microscopy images of the released aerosol show mostly submicron aggregates with spherical nano-features (Supplemental Figure 4).

\subsection{Extraction of LCPM from collection media}

Due to the hydrophobic nature of LCPM and the constituent polymer matrices, the ethanol extraction protocol from the SEDD methodology was utilized. The resulting extraction efficiency (EE\%) was $97 \%$ for all LCPM. Using a delivered sonication of $466 \mathrm{~J} / \mathrm{ml}$ the majority of LCPM mass was recovered from collection media with minimal alteration or destruction of Teflon filters.

\subsection{LCPM dispersion and colloidal characterization}

Table 2 summarizes the LCPM size distributions within deionized water $\left(\mathrm{DiH}_{2} \mathrm{O}\right)$ and SABM media. Hydrodynamic diameter $\left(\mathrm{d}_{\mathrm{H}}\right)$, zeta potential $(\zeta)$, polydispersity $(\mathrm{PdI})$, conductance, and $\mathrm{pH}$ over $24 \mathrm{~h}$ are displayed after initial sonication revealing the stability of the colloidal suspensions. The delivered sonication energy for the majority of the particles was $1066 \mathrm{~J} / \mathrm{ml}$. The average hydrodynamic diameter of PU LCPM suspended in water was $637.8 \mathrm{~nm}$ and in SABM $544.5 \mathrm{~nm}$. The average hydrodynamic diameter of PU-CNT LCPM suspended in water was $554.2 \mathrm{~nm}$ and in SABM $594.0 \mathrm{~nm}$. The $\zeta$ for the PU LCPM were positive in water, and became negative when dispersed in to SABM media. For PE the average hydrodynamic diameter in water was $528.7 \mathrm{~nm}$. After dispersion in SABM, the average hydrodynamic diameter for PE was reduced to $347.5 \mathrm{~nm}$. PE $\mathrm{Fe}_{2} \mathrm{O}_{3} \mathrm{LCPM}$ average hydrodynamic diameter in water and in SABM 
was similar. LCPM derived from EVA only displayed similar average hydrodynamic diameters in both water and SABM. Interestingly, the average $\mathrm{d}_{\mathrm{H}}$ for LCPM derived from EVA $2 \% \mathrm{TiO}_{2}$ was larger in water and became smaller upon dispersion in SABM media. The PdI for majority of the LCPM was less than 0.6 suggesting the suspensions were polydisperse. Colloidal characterization for the raw nanofillers can be found in Supplemental Table 2. Briefly, the reference control, carbon nanotubes, (CNT) formed fairly large agglomerates in water but reduced by half once dispersed into $\mathrm{SABM}$ media. $\mathrm{TiO}_{2}$ nanoparticles (NPs) formed large agglomerates in water and became smaller once dispersed in SABM. $\mathrm{Fe}_{2} \mathrm{O}_{3}$ NPs used as the nanofiller in $\mathrm{PE} \mathrm{Fe}_{2} \mathrm{O}_{3}$ formed slightly larger agglomerates once dispersed into SABM. In addition to the colloidal characterization, the effective density was measured using the VCM method and is summarized in Table 2. Finally, endotoxin in the samples tested was below the limit of detection $(0.005 \mathrm{EU} / \mathrm{ml})$ at $10 \mu \mathrm{g} / \mathrm{ml}$, and the samples showed no evidence of assay inhibition based on results from samples spiked with $0.5 \mathrm{EU} / \mathrm{ml}$ of endotoxin standard.

\subsection{In vitro dosimetric analysis}

Table 3 summarizes the dosimetric considerations such as the concentration over time, fraction deposited and the mean mass delivered per $\mathrm{cm}^{2}$ at the bottom of the well for each dose of the LCPM evaluated. Efforts were made to obtain similar delivered to cell doses across various LCPMs by adjusting the administered LCPM concentration to account for differential settling rates. At the bottom of the well, an increase in concentration was shown over the course of exposure for each LCPM group with an effective density equal to or greater than the culture media. Delivered to cell doses were matched (within 10-15\% range) for the majority of all LCPM and doses.

It is worth noting that due to extremely low effective densities of formed agglomerates from LCPM derived from PP and PP-CNT $\left(0.9 \mathrm{~g} / \mathrm{cm}^{3}\right)$ in comparison to SABM media density, these particular LCPM were determined to be buoyant. The reported concentrations and delivered to cell doses per square area for PP and PP-CNT LCPM are the average accumulation at the top of the well over $24 \mathrm{~h}$ and the inverted exposure system was utilized as described in the methods section above. Dosimetric considerations for the comparator materials or the pristine nanofillers were also derived and can be found in Supplemental Table 3. 

exposures

413 Carbonaceous Nanofiller. We evaluated the toxicological profiles of LCPM derived from incinerated polyurethane (PU), containing $0.1 \%$ carbon nanotubes (PU-CNT). After $24 \mathrm{hr}$ exposure of delivered to cell doses, there was a clear elevation in reactive oxygen species in each exposure group (no nanofiller control and pristine ENM comparator) in comparison to the media alone groups (Figure 1A). We observed a clear nanofiller effect in ROS generation assessment, which corresponded to a significant reduction in total glutathione levels in SAEC due to PUCNT LCPM in comparison to the PU only exposure group indicating increased levels of oxidative stress (Figure 1B). As oxidative stress is an early harbinger of cytotoxicity, we evaluated the metabolic activity of SAEC after LCPM exposures. A marked decrease in mitochondrial membrane potential was found (Figure 1C), which coincided with a decrease in cellular viability (Figure 1D). Pristine CNT exposures showed dose dependent responses in which significant decreases in total glutathione, mitochondrial membrane potential and cell viability were found in comparison to media only controls. However, the observed reductions were not greater than PU-CNT LCPM. Evaluations of LCPM only did not impose any issues with results or interference with reagent integrity (data not shown).

Metal Oxide Nanofillers: To evaluate the biological activity of LCPM from thermally decomposed nanocomposites containing metal oxide nanofillers, we compared similar doses of the following LCPM exposure groups of polyethylene (PE) alone and LCPM derived from PE 5\% $\mathrm{Fe}_{2} \mathrm{O}_{3}$ ), and the raw $\mathrm{Fe}_{2} \mathrm{O}_{3} \mathrm{ENM}$ /nanofiller used in the nanocomposite. Twenty-four hour exposures of LCPM derived from PE $5 \% \mathrm{Fe}_{2} \mathrm{O}_{3}$ resulted in a significant increase in reactive oxygen species in comparison to media only controls, however no nanofiller effect was observed (Figure 2A). Significant reductions in total glutathione levels (Figure 2B) due to PE only and PE $5 \% \mathrm{Fe}_{2} \mathrm{O}_{3}$ LCPM where the reduction in total glutathione was greater in the case of LCPM derived from $\mathrm{PE} 5 \% \mathrm{Fe}_{2} \mathrm{O}_{3}$ (low and high dose) indicating a nanofiller effect. In comparison to media control, we found a reduction in mitochondrial membrane potential due to LCPM derived from PE alone and PE 5\% $\mathrm{Fe}_{2} \mathrm{O}_{3} \mathrm{LCPM}$ (Figure 2C), however, no clear nanofiller related effects were apparent. Additionally, a marked reduction in cellular viability was shown in the case of 
PE 5\% $\mathrm{Fe}_{2} \mathrm{O}_{3}$ in comparison to $\mathrm{PE}$ only (Figure 2D). We also reveal the low toxicity and biological activity of the pristine nanofiller, $\mathrm{Fe}_{2} \mathrm{O}_{3}$, in each of our toxicological endpoints.

\subsection{Effect of nanofiller loading on dose response relationships}

Establishing dose response relationships is an essential component of nanotoxicology and risk assessment. To determine if the dose response is influenced by increasing nanofiller loading during the thermodecomposition of nanocomposites, we evaluated and compared similar doses of LCPM derived from thermally decomposed ethylene vinyl acetate (EVA) with increasing nanofiller loading of titania ( 2 and $5 \% \mathrm{w} / \mathrm{v}$ ) and EVA alone. There was a significant increase or elevation in reactive oxygen species due to LCPM exposures derived from thermally decomposed EVA containing 2 and 5\% $\mathrm{TiO}_{2}$ in comparison to EVA alone (Control) (Figure 3A) independent of dose. Likewise, marked reductions of total glutathione were shown due to all doses of EVA containing 2 and $5 \% \mathrm{TiO}_{2}$ revealing significant drops in antioxidant levels over a $24 \mathrm{~h}$ exposure (Figure 3B). This overwhelming reduction in antioxidant levels and the increase in ROS, greatly diminished the mitochondrial membrane potential in exposure groups of EVA 2 and $5 \% \mathrm{TiO}_{2}$ (Figure 3C), leading to a severe decrease in cellular viability (Figure 3D). Conversely, SAEC responses to the pristine nanofiller were minimal revealing the low toxicity of titanium dioxide ENMs at these particular doses and duration. These results indicate no obvious dose dependent response in the utilized doses of EVA 2 and 5\% $\mathrm{TiO}_{2} \mathrm{LCPM}$; however, there is enhanced biological activity and toxicity of LCPM due to the presence of titania during the thermal decomposition process of EVA.

\subsection{Influence of host matrix on toxicological profile of LCPM}

To determine the host matrix influence on LCPM toxicity, we evaluated two separate NEP, polycarbonate (PC) and polypropylene (PP) both containing 3\% carbon nanotubes. Exposures of PC alone and PC-CNT (3\% w/v) LCPM (Supplemental Figure 5) promoted an elevation in reactive oxygen species at each dose in SAEC (Supplemental Figure 5A). This resulted in a dose dependent reduction in total glutathione in both PC alone and PC-CNT LCPM exposure groups, indicating both groups induced equivalent amounts of oxidative stress (Supplemental Figure 5B). We observed similar reductions in mitochondrial function (Supplemental Figure 5C) and cellular viability (Supplemental Figure 5D) due to PC alone and PC-CNT LCPM exposures, which along 
with previously mentioned outcomes suggests that the host matrix, polycarbonate, dictates the observed cellular responses not the nanofiller at this percent loading. Similarly, we did not observe a distinction in cellular responses between PP alone and PP-CNT (3\% w/v) exposure groups at equivalent doses (Supplemental Figure 6). PP and PP-CNT LCPM exposures, at each delivered dose elicited a significant increase in reactive oxygen species (Supplemental Figure 6A) in comparison to media only controls in SAEC. Supplemental Figure 6B shows the resulting oxidative stress, where total glutathione levels where significantly reduced at equivalent levels due to PP alone and PP-CNT LCPM. We found no differences between exposure groups in regards to mitochondrial function (Supplemental Figure 6C) or metabolic activity (Supplemental Figure 6D); however, reductions were significant when comparing to the media alone control. Together, these data suggest that the host matrices, PC and PP, both possess properties that overshadow potential nanofiller effects and significantly contribute to the observed adverse outcomes.

\subsection{LCPM mediated DNA damage in SAEC}

Using the previously developed CometChip platform, we assessed the genotoxic potential of selected LCPM. PU alone and PU-CNT displayed similar genotoxic potential with minimal amounts of single stranded DNA damage induced (Figure 4A). Although, no nanofiller effect was found in the cytotoxicity assessment of PC and PC-CNT LCPM exposures, we observed an nano-filler effect where more single stranded DNA (ssDNA) breaks where found due to PC-CNT LCPM in comparison to PC alone exposures at the highest dose (Figure 4B). In Figure 4C, PE and PE containing $\mathrm{Fe}_{2} \mathrm{O}_{3}$ LCPM exposures displayed similar results as both increased ssDNA damage in a dose dependent manner, thus no nanofiller effect was found for this particular particle system in regards to genotoxicity. In comparison to the positive control of hydrogen peroxide $\left(\mathrm{H}_{2} \mathrm{O}_{2}\right)$, the DNA damage potential of the evaluated LCPM is relatively low.

\subsection{Discussion}

The toxicological profiles of aerosols emanating from thermally decomposed nano-enabled thermoplastics highlight the importance of assessing the implications of nano-enabled products 
across their life cycle. In the present study, a number of hypotheses were investigated in order to make the link between properties of ENMs (nanofillers) (i.e. organic/inorganic per weight nanofiller loading) and type of matrix to toxicological outcomes. Emphasis was given to assess if the presence of nanofillers can increase or inhibit toxicological potential of thermoplastics during thermal decomposition. This is of great importance as certain ENM can release soluble ions, generate reactive oxygen species, and disturb cellular processes necessary for homeostasis. Yet many questions remain in regards to the potential release of ENMs across the life cycle of NEP and their potential transformations during the release process. LCPM particles are more complex particle systems and may or may not contain the pristine ENMs in their exact form used in the NEP synthesis. It was shown in our companion studies that the inorganic/organic nature of nanofiller has an effect on the potential release of ENMs during thermal composition (Singh et al., in revision); (Sotiriou et al., 2016). Of interest of course is not just to assess the potential release of ENMs during thermal decomposition, but to determine how these property transformations and interactions with gaseous pollutants can result in particles that are more or less toxic compared to the thermal decomposition of pristine thermoplastic material (no nanofiller) and assess the potential of such a nanofiller effect.

It is also worth noting that in this study, special focus on in-vitro dosimetry was given in order to compare across different LCPM systems and also to assess potential differences compared to the polymer only (no nanofiller) control. This was made possible by utilizing the integrated in-vitro dosimetry platform recently developed by the authors, which enables estimation of delivered to cell dose rate as a function of exposure time (Cohen, et al., 2013; Cohen et al., 2015; DeLoid, et al., 2014; DeLoid, et al., 2015),(Pal et al., 2015a);(Palza, 2015). Using this integrated, multistep methodology, the fraction deposited of each LCPM colloid as a function of time was derived and the necessary administered concentration was adjusted across different LCPM colloids in order to bring at the same level, the delivered to cell doses across various particle systems. The delivered to cell doses evaluated in this study were used to cover a range of low and high doses to explore the toxicological properties of LCPM.

\section{Hypothesis 1 - Impact of Nanofiller Composition on Toxicological Outcomes: The physico-} chemical properties of the utilized nanofillers such as shape and composition can elicit adverse effects in biological systems including cytotoxicity, inflammation, and genotoxicity (Mu et al., 
2016; Nel et al., 2013). The inclusion of nanofillers in polymers and their subsequent release during thermal decomposition prompts the inevitable question - can nanofiller intrinsic properties play a role on the release potential and subsequently influence toxicological profile when compared to the polymer only control? As shown in our recently published companion papers (Sotiriou et al., 2016, Singh et al. in revision), only in the case of inorganic nanofillers such as iron oxide and titania was there a potential for a release in the aerosol during thermal decomposition. There was no release in the air of ENMs for organic nanofillers such as CNTs at their pristine phase, however trace metals present in CNTs were released in the air and found in the LCPM. Based on the toxicological findings from this study, we observed an obvious nanofiller effect where higher toxicity was observed due to PU-CNT LCPM in comparison to exposures to PU alone. It is worth noting that although no carbon nanotubes were found in the released aerosol of PU-CNT, a small percentage of aluminum was found in the released aerosols (Sotiriou et al., 2016), which may have contributed to the observed cellular responses and genotoxicity. These toxicological findings correlate well with studies investigating low dose exposures to aluminum and adverse cellular effects (Chen et al., 2008; Clausen et al., 2003; Di Virgilio et al., 2010). An alternative mechanism of action could be related to the presence of toxic PAHs during the thermal decomposition of polyurethane. Polycyclic aromatic hydrocarbons are well known for their potential to induce acute toxicity in various biological systems. Classical cellular responses to PAH exposure involves mitochondrial dysfunction, oxidative stress, depletion of ATP, cellular viability reduction (Pavanello et al., 2013), which are clearly shown in our results. Importantly, synergistic effects between PAHs and particles could also play a role in the observed toxicity. While the occurrence of PAH production during thermal decomposition of polymers is well known, studies evaluating the promotion of high molecular weight PAH due to the presence of metal nanofillers is limited (Duncan, 2015). Studies investigating the role of nanofiller and host polymer matrices in PAH production during thermal decomposition are currently underway in our group along with detailed PAH characterization on all LCPM particles from this study.

Unlike PU-CNT where no carbon nanotubes were released in the air during the incineration process, traces of iron oxide release were found in PE containing 5\% $\mathrm{Fe}_{2} \mathrm{O}_{3} \mathrm{LCPM}$. We show that the presence of $\mathrm{Fe}_{2} \mathrm{O}_{3}$ nanofiller induced higher toxicity and biological activity than aerosols from the control (PE, no nanofiller). Importantly, these results also differed greatly from the 
$\mathrm{Fe}_{2} \mathrm{O}_{3}$ nanofiller or comparator material used in the nanocomposite synthesis, which showed no significant biological activity or toxicity in SAEC. We have shown in previous studies that raw iron oxide ENMs are thought to be biocompatible and inert, and hold minimal toxic potential (Watson et al., 2015), which suggests other mechanisms or properties may be influencing the observed toxicity of PE 5\% $\mathrm{Fe}_{2} \mathrm{O}_{3}$ LCPM exposures.

Furthermore, it is worth noting that a dose dependent increase in single stranded DNA damage was observed for both PE and PE 5\% $\mathrm{Fe}_{2} \mathrm{O}_{3}$ LCPM. Interestingly, there was no significant difference between in the evaluated particle systems or a nanofiller effect in regards to genotoxicity. Previous studies in other labs and our lab have demonstrated the genotoxic potential of pristine iron oxide ENMs (Alarifi et al., 2014; Watson, et al., 2013). The biocompatibility and utility of nanocomposites containing iron oxide is described in various studies (Meyer and Green, 2015). Our observations suggest an enhancement of genotoxicological properties of released particles from thermally decomposed iron containing nanocomposites indicating a potential environmental health and safety concern. However, since the concentrations chosen induce some cell viability reduction (less than 50\%), it is not evident if the LCPM particles are solely responsible for the observed DNA damage or if these findings are merely "secondary effects" due to the assessment of injured cells.

Hypothesis 2 - Nano-filler Loading Influence on Dose Response Relationships: Our initial hypothesis stated that increasing the nanofiller percentage within the host matrix will influence dose response relationships. In this study, we determined that increasing the nanofiller loading of $\mathrm{TiO}_{2}$ from 2-5\% w/v in EVA prevented derivation of a dose response relationship as each dose was equally toxic. Although the EVA alone LCPM exposures (control) exhibited significant toxicity in small airway epithelial cells, the astounding difference in the toxicological profiles of EVA polymer LCPM and EVA containing $\mathrm{TiO}_{2}$ suggests that a nanofiller effect is apparent regardless of $\mathrm{TiO}_{2}$ nanofiller loading amounts. The reported findings may also be attributed to the high residual $\mathrm{TiO}_{2}$ levels (Supplemental Figure 3) within the released aerosols, which were 1 and 2.4 weight $\%$ for LCPM generated from thermally decomposed EVA containing $2 \% \mathrm{w} / \mathrm{v}$ and $5 \% \mathrm{w} / \mathrm{v} \mathrm{TiO}_{2}$. This coincides with reports in the literature of harmful effects after exposure to $\mathrm{TiO}_{2}$ ENMs in numerous cellular systems, with the main mode of action being oxidative stress (Saquib et al., 2012; Shukla et al., 2011; Srivastava et al., 2013). While this could be a 
plausible explanation, the pristine $\mathrm{TiO}_{2}$ ENMs we evaluated as comparator materials induced minimal cellular injury, which suggests other factors must be involved that may be related to the complex chemistry of LCPM. For example, Singh et al postulated that although increasing the $\mathrm{TiO}_{2}$ loading had no influence over the elemental and organic carbon content of the released aerosols, there could be differences in the speciation of the released organic compounds. These differences could play a major role in the biological activity of EVA based LCPM. Studies to evaluate this hypothesis are currently being investigated.

Toxicity of Host Matrix Only LCPM. Within the literature there is evidence indicating the host matrix influences the release kinetics and properties of released PM during thermal decomposition (Hirth et al., 2013; Sotiriou, et al., 2016; Sotiriou, et al., 2015). Moreover, numerous studies have linked toxins and particles released from thermally decomposed polymers to toxicity in cellular systems (Kitahara, et al., 2010). This information warrants an evaluation of the toxicological properties of the host matrix or polymer only LCPM when introduced to biological systems. In two of our particle systems, polycarbonate (PC) and polypropylene (PP), we found that the host matrix elicited similar biological activity and toxicity than the nanocomposite form containing 3\% carbon nanotubes. This suggests that the host matrix only LCPM possess a high level of toxicity themselves and overshadow potential nanofiller effects. Interestingly, we did observe a nanofiller related effect in our genotoxicity assessments of polycarbonate and polycarbonate containing CNTs LCPM, where PC-CNT induced more single stranded DNA damage than PC alone LCPM.

In toto, the LCPM emitted from thermally decomposed polycarbonate and polypropylene were highly toxic and dwarfed potential toxicological effects of the CNT nanofiller $(3 \% \mathrm{w} / \mathrm{v})$. These findings differ greatly from polyurethane containing $0.1 \%$ carbon nanotubes (PU-CNT), where a nanofiller effect was demonstrated in SAEC responses. It is counter-intuitive that less nanofiller loading would be more toxic than higher loadings of the carbon nanotubes. However, studies in the literature have noted the ability of carbon nanotubes to act as free radical scavengers and their affinity to adsorb various organic chemicals (Diaz et al., 2007; Pan and Xing, 2008). Thus, possibly the higher loadings of carbon nanotubes $(3 \% \mathrm{w} / \mathrm{v})$ in polycarbonate and polypropylene may have reduced hazardous byproducts, whereas the lower loading found in polyurethane $(0.1 \% \mathrm{w} / \mathrm{v})$ may not have been sufficient for adsorption. 


\section{Conclusions}

620 In this companion study, toxicological comparisons of aerosols emitted and collected during the

621

622

623

624

625

626

627

628

629

630

631

632

633

634

635

636

637

638

639

640

641

642

643

644 thermodecomposition of nano-enabled thermoplastics were performed to determine potential nanofiller effects. We observed nanofiller effects where higher levels of toxicity and biological activity were found due to exposures of aerosols emitted from certain nanocomposites including polyurethane containing $0.1 \%$ carbon nanotubes, polyethylene containing $5 \%$ iron oxide, and ethylene vinyl acetate containing 2 and 5\% titanium dioxide ENMs in comparison to the aerosols released from their host matrices (controls). The properties of embedded nanofiller such as chemistry, shape and composition may have played a role in the observed nanofiller effect. A certain percentage of nanofiller loading enhanced the nanofiller effect regardless of delivered to cell dose, which could be related to the generation and adsorption of hazardous byproducts on LCPM during the thermo-decomposition of nano-enabled thermoplastics. Finally, aerosols derived from the thermodecomposition of certain thermoplastics such as polypropylene and polycarbonate induced toxicity similar to that of nano-enabled thermoplastic LCPM, which indicates certain thermoplastics are more hazardous than others. The findings of this study indicate the hazards of incinerated nano-enabled thermoplastics while underscoring the need to further study life cycle nano-release scenarios and associated byproducts.

\section{Acknowledgements}

This research was supported by the National Science Foundation (NSF grant no. 1436450) and National Institute of Health (NIH S10 grant no. 1S10OD020086). We thank S. Pirela, X. Lu, and G. DeLoid for their assistance in LCPM preparation and endotoxin testing, respectively. C.W.W. was funded by the NIH NHLBI Ruth L. Kirschstein T32 training grant (NIH HL007118) and the Harvard Yerby Fellowship.

43 Tables

Table 1. Thermoplastics, related nanocomposites, and nanofillers used in study
Nanofiller
Source

Applications 


\begin{tabular}{ccccc}
\hline Polyurethane & $\begin{array}{c}\text { Carbon nanotubes } \\
(\mathrm{CNT})\end{array}$ & $0.1 \%$ & BASF & $\begin{array}{c}\text { Automotive, buildings, } \\
\text { textiles }\end{array}$ \\
\hline $\begin{array}{c}\text { Polyethylene } \\
\text { (PE) }\end{array}$ & $\mathrm{Fe}_{2} \mathrm{O}_{3}$ & $5 \%$ & MARINA & $\begin{array}{c}\text { Packaging, buildings, } \\
\text { construction }\end{array}$ \\
\hline $\begin{array}{c}\text { Polycarbonate } \\
\text { (PC) }\end{array}$ & $\mathrm{CNT}$ & $3 \%$ & $\begin{array}{c}\text { Synthesized in- } \\
\text { house }\end{array}$ & $\begin{array}{c}\text { Automotive, } \\
\text { electronics }\end{array}$ \\
\hline $\begin{array}{c}\text { Polypropylene } \\
\text { (PP) }\end{array}$ & $\mathrm{CNT}$ & $3 \%$ & $\begin{array}{c}\text { Synthesized in- } \\
\text { house }\end{array}$ & Packaging, electronics \\
\hline $\begin{array}{c}\text { Ethylene vinyl } \\
\text { acetate (EVA) }\end{array}$ & $\mathrm{TiO}_{2}$ & $2 \%$ and $5 \%$ & $\begin{array}{c}\text { Synthesized in- } \\
\text { house }\end{array}$ & $\begin{array}{c}\text { Packaging, biomedical } \\
\text { devices }\end{array}$
\end{tabular}

645

646

647

648

649

650

651

652

Footnotes: Materials were provided through a collaboration with EU, FP 7MARINA (Managing Risks of Nanoparticles) Project Reference\#: 263215; Materials synthesized in-house; Polyurethane was obtained from a collaboration with BASF - Ludwigshafen, Germany; LCPM derived from incinerated host polymer matrices (no nanofiller) was used as reference controls.

Table 2. Colloidal characterization of aerosolized particulate matter (LCPM) in aqueous media. Hydrodynamic diameter $\left(\mathrm{d}_{\mathrm{H}}(\mathrm{h}, \mathrm{z}\right.$-ave) $)$, polydispersity $(\mathrm{PdI})$, zeta potential $(\mathrm{mV})$, and conductance $(\mathrm{mS} / \mathrm{cm})$ of LCPM in DI water at $\mathrm{DSE}_{\mathrm{cr}}$ (critical delivered sonication energy) and after particle dispersion in SABM using DLS method after $24 \mathrm{hr}$. The DSE $\mathrm{cr}_{\mathrm{cr}}$ utilized was $1066 \mathrm{~J} / \mathrm{ml}$.

\begin{tabular}{|c|c|c|c|c|c|c|c|}
\hline LCPM & Media & $\begin{array}{c}\mathbf{d}_{(\mathbf{h}, \mathbf{z} \text {-ave })} \\
(\mathrm{nm})\end{array}$ & PdI & $\begin{array}{c}\text { Zeta } \\
\text { Potential } \\
\zeta(\mathrm{mV})\end{array}$ & $\begin{array}{c}\text { Conductance } \\
\sigma(\mathrm{mS} / \mathrm{cm})\end{array}$ & pH & $\begin{array}{c}\boldsymbol{\rho}_{\text {agg }} \\
\left(\mathrm{g} / \mathrm{cm}^{3}\right)\end{array}$ \\
\hline \multirow{2}{*}{ PU } & DI water & $637.8 \pm 7.1$ & $0.41 \pm 0.03$ & $6.13 \pm 1.34$ & $0.48 \pm 0.10$ & - & - \\
\hline & SABM & $544.5 \pm 51.3$ & $0.39 \pm 0.07$ & $-13.6 \pm 2.4$ & $11.6 \pm 1.9$ & 7.52 & 1.134 \\
\hline \multirow{2}{*}{ PU-CNT } & DI water & $554.2 \pm 32.0$ & $0.34 \pm 0.06$ & $11.3 \pm 0.78$ & $0.28 \pm 0.03$ & - & - \\
\hline & SABM & $595.0 \pm 11.8$ & $0.74 \pm 0.11$ & $-28.7 \pm 2.3$ & $-1.5 \pm 0.5$ & 7.43 & 1.148 \\
\hline \multirow{2}{*}{ PE800 } & DI $\mathrm{H}_{2} \mathrm{O}$ & $528.7 \pm 16.4$ & $0.35 \pm 0.08$ & $-14.5 \pm 0.9$ & $0.011 \pm 0.57$ & - & - \\
\hline & SABM & $347.5 \pm 42$ & $0.44 \pm 0.09$ & $-15.3 \pm 0.4$ & $11.7 \pm 0.4$ & 7.53 & 0.96 \\
\hline \multirow{2}{*}{$\begin{array}{c}\text { PE800 } \\
5 \% \mathrm{Fe}_{2} \mathrm{O}_{3}\end{array}$} & $\mathrm{DI} \mathrm{H}_{2} \mathrm{O}$ & $204.5 \pm 25.3$ & $0.32 \pm 0.07$ & $-23.7 \pm 2.5$ & $-1.86 \pm 0.19$ & - & - \\
\hline & SABM & $204.6 \pm 13.9$ & $0.29 \pm 0.01$ & $-15.3 \pm 1.5$ & $-1.03 \pm 0.1$ & 7.43 & 0.953 \\
\hline \multirow{2}{*}{ EVA } & $\mathrm{DI} \mathrm{H}_{2} \mathrm{O}$ & $147 \pm 2.1$ & $0.35 \pm 0.08$ & $-42.7 \pm 7.8$ & $0.027 \pm 0.002$ & - & - \\
\hline & SABM & $146 \pm 5.8$ & $0.26 \pm 0.02$ & $-14.5 \pm 3.6$ & $10.9 \pm 0.32$ & 7.3 & 0.96 \\
\hline EVA & DI $\mathrm{H}_{2} \mathrm{O}$ & $470 \pm 47.9$ & $0.17 \pm 0.04$ & $-39.7 \pm 2.2$ & $0.02 \pm 0.0001$ & - & - \\
\hline
\end{tabular}




\begin{tabular}{|c|c|c|c|c|c|c|c|}
\hline $2 \% \mathrm{TiO}_{2}$ & SABM & $379.1 \pm 50.1$ & $0.25 \pm 0.006$ & $-13.5 \pm 0.5$ & $10.6 \pm 0.44$ & 7.41 & 0.955 \\
\hline \multirow{2}{*}{$\begin{array}{c}\text { EVA } \\
5 \% \mathrm{TiO}_{2}\end{array}$} & $\mathrm{DI} \mathrm{H}_{2} \mathrm{O}$ & $471 \pm 18.3$ & $0.89 \pm 0.01$ & $-35.4 \pm 0.7$ & $0.022 \pm 0.0003$ & - & - \\
\hline & SABM & $418.7 \pm 26.5$ & $0.45 \pm 0.03$ & $-15.4 \pm 2.4$ & $12.5 \pm 1.4$ & 7.51 & 0.945 \\
\hline \multirow{2}{*}{ PC } & DI water & $349 \pm 3.42$ & $0.35 \pm 0.04$ & $-39.2 \pm 2.1$ & $0.028 \pm 0.0003$ & - & - \\
\hline & SABM & $397.5 \pm 22.7$ & $0.44 \pm 0.04$ & $-13.6 \pm 2.4$ & $10.7 \pm 1.9$ & 7.52 & 1.134 \\
\hline \multirow{2}{*}{ PC-CNT } & DI water & $322.0 \pm 1.9$ & $0.18 \pm 0.02$ & $-27.9 \pm 1.3$ & $0.031 \pm 0.03$ & - & - \\
\hline & SABM & $385.7 \pm 20.9$ & $0.21 \pm 0.02$ & $-13.7 \pm 0.5$ & $10.7 \pm 0.2$ & 7.43 & 1.148 \\
\hline \multirow[t]{2}{*}{ PP } & DI water & $461.1 \pm 14.2$ & $0.41 \pm 0.04$ & $-44.1 \pm 4.3$ & $0.007 \pm 0.0001$ & - & - \\
\hline & SABM & $239.7 \pm 1.7$ & $0.46 \pm 0.04$ & $-49.8 \pm 6.5$ & $11.9 \pm 0.9$ & 7.51 & 0.9 \\
\hline \multirow{2}{*}{ PP-CNT } & DI water & $422.8 \pm 5.2$ & $0.28 \pm 0.02$ & $-40.5 \pm 3.9$ & $0.015 \pm 0.002$ & - & - \\
\hline & SABM & $358.6 \pm 6.0$ & $0.41 \pm 0.03$ & $-19.7 \pm 1.3$ & $6.4 \pm 0.4$ & 7.52 & 0.91 \\
\hline
\end{tabular}

653

654

655

656

657

658

659

660

661

662

663

664
Table 3. Dosimetry summary. The administered concentration and delivered dose metrics determined across $24 \mathrm{~h}$ LCPM exposure using the DG model with inputs such as the volume weighted hydrodynamic diameter in SABM media as determined by DLS and VCM method.

\begin{tabular}{|c|c|c|c|c|c|c|c|c|c|c|c|}
\hline \multicolumn{4}{|c|}{ Administered Dose $\left(\mu \mathrm{g} \mathrm{ml}^{-1}\right)$} & \multicolumn{4}{|c|}{ Administered Dose $\left(\mu \mathrm{g} \mathrm{ml}^{-1}\right)$} & \multicolumn{4}{|c|}{ Administered Dose $\left(\mu \mathrm{g} \mathrm{ml}^{-1}\right)$} \\
\hline PU & 0.76 & 7.64 & 76.4 & $\mathbf{P E}$ & 50 & 100 & 200 & EVA & 100 & 300 & 400 \\
\hline \multicolumn{4}{|c|}{ Delivered to cell dose metrics } & \multicolumn{4}{|c|}{ Delivered to cell dose metrics } & \multicolumn{4}{|c|}{ Delivered to cell dose metrics } \\
\hline$\mu \mathrm{g} \mathrm{ml}^{-1}$ & 6.667 & 66.67 & 666.7 & $\mu \mathrm{g} \mathrm{ml}^{-1}$ & 29.7 & 69.5 & 149.0 & $\mu \mathrm{g} \mathrm{ml}^{-1}$ & 86.1 & 258.4 & 344.4 \\
\hline$f_{D}(t)$ & 0.29 & 0.29 & 0.29 & $f_{D}(t)$ & 0.013 & 0.013 & 0.013 & $f_{D}(t)$ & 0.026 & 0.026 & 0.026 \\
\hline$\mu \mathrm{g} \mathrm{cm}^{-2}$ & 0.066 & 0.666 & 6.66 & $\mu \mathrm{g} \mathrm{cm}^{-2}$ & 0.29 & 0.69 & 1.49 & $\mu \mathrm{g} \mathrm{cm}^{-2}$ & 0.86 & 2.58 & 3.44 \\
\hline \multicolumn{4}{|c|}{ Administered Dose $\left(\mu \mathrm{g} \mathrm{ml}^{-1}\right)$} & \multicolumn{4}{|c|}{ Administered Dose $\left(\mu \mathrm{g} \mathrm{ml}^{-1}\right)$} & \multicolumn{4}{|c|}{ Administered Dose $\left(\mu \mathrm{g} \mathrm{ml}^{-1}\right)$} \\
\hline PU-CNT & 0.05 & 5 & 50 & PE 5\% Fe & 50 & 100 & 200 & $\begin{array}{c}\text { EVA } \\
2 \% \mathrm{TiO}_{2}\end{array}$ & 325 & 1000 & 1300 \\
\hline
\end{tabular}




\begin{tabular}{|c|c|c|c|c|c|c|c|c|c|c|c|}
\hline \multicolumn{4}{|c|}{ Delivered to cell dose metrics } & \multicolumn{4}{|c|}{ Delivered to cell dose metrics } & \multicolumn{4}{|c|}{ Delivered to cell dose metrics } \\
\hline$\mu \mathrm{g} \mathrm{ml}^{-1}$ & 5.945 & 59.45 & 594.5 & $\mu \mathrm{g} \mathrm{ml}^{-1}$ & 38.5 & 77.2 & 154.3 & $\mu \mathrm{g} \mathrm{ml}^{-1}$ & 77.9 & 239.9 & 311.8 \\
\hline $\mathrm{f}_{\mathrm{D}}(\mathrm{t})$ & 0.39 & 0.39 & 0.39 & $\mathrm{f}_{\mathrm{D}}(\mathrm{t})$ & 0.015 & 0.015 & 0.015 & $\mathrm{f}_{\mathrm{D}}(\mathrm{t})$ & 0.001 & 0.001 & 0.001 \\
\hline$\mu \mathrm{g} \mathrm{cm}^{-2}$ & 0.059 & 0.594 & 5.94 & $\mu \mathrm{g} \mathrm{cm}^{-2}$ & 0.38 & 0.77 & 1.54 & $\mu \mathrm{g} \mathrm{cm}^{-2}$ & 0.77 & 2.39 & 3.11 \\
\hline \multicolumn{4}{|c|}{ Administered Dose $\left(\mu \mathrm{g} \mathrm{ml}^{-1}\right)$} & \multicolumn{4}{|c|}{ Administered Dose $\left(\mu \mathrm{g} \mathrm{ml}^{-1}\right)$} & \multicolumn{4}{|c|}{ Administered Dose $\left(\mu \mathrm{g} \mathrm{ml}^{-1}\right)$} \\
\hline $\mathbf{P C}$ & 0.5 & 5 & 50 & PC-CNT & 0.5 & 5 & 50 & $\begin{array}{c}\text { EVA } \\
\mathbf{5} \% \mathrm{TiO}_{2}\end{array}$ & 325 & 1000 & 1300 \\
\hline \multicolumn{4}{|c|}{ Delivered to cell dose metrics } & \multicolumn{4}{|c|}{ Delivered to cell dose metrics } & \multicolumn{4}{|c|}{ Delivered to cell dose metrics } \\
\hline$\mu \mathrm{g} \mathrm{ml}^{-1}$ & 1.88 & 18.88 & 188.8 & $\mu \mathrm{g} \mathrm{ml}^{-1}$ & 1.91 & 19.11 & 191.1 & $\mu \mathrm{g} \mathrm{ml}^{-1}$ & 75.1 & 218.9 & 284.5 \\
\hline$f_{D}(t)$ & 0.13 & 0.13 & 0.13 & $\mathrm{f}_{\mathrm{D}}(\mathrm{t})$ & 0.14 & 0.14 & 0.14 & $\mathrm{f}_{\mathrm{D}}(\mathrm{t})$ & 0.001 & 0.001 & 0.001 \\
\hline$\mu \mathrm{g} \mathrm{cm}^{-2}$ & 0.018 & 0.18 & 1.88 & $\mu \mathrm{g} \mathrm{cm}^{-2}$ & 0.019 & 0.19 & 1.91 & $\mu \mathrm{g} \mathrm{cm}^{-2}$ & 0.75 & 2.18 & 2.84 \\
\hline \multicolumn{4}{|c|}{ Administered Dose $\left(\mu \mathrm{g} \mathrm{ml}^{-1}\right)$} & \multicolumn{4}{|c|}{ Administered Dose $\left(\mu \mathrm{g} \mathrm{ml}^{-1}\right)$} & \multirow{3}{*}{\multicolumn{4}{|c|}{$\begin{array}{l}\text { Footnote: } \\
\text { Concentrations and doses per square } \\
\text { area for PP and PP-CNT LCPM are for } \\
\text { the top of the well. }\end{array}$}} \\
\hline PP & 50 & 100 & 250 & PP-CNT & 29.5 & 59.17 & 147.9 & & & & \\
\hline \multicolumn{4}{|c|}{ Delivered to cell dose metrics } & \multicolumn{4}{|c|}{ Delivered to cell dose metrics } & & & & \\
\hline$\mu \mathrm{g} \mathrm{ml}^{-1}$ & 77.6 & 155.3 & 388.5 & $\mu \mathrm{g} \mathrm{ml}^{-1}$ & 77.6 & 155.9 & 389.5 & \multirow{3}{*}{\multicolumn{4}{|c|}{$\begin{array}{l}\text { For all other LCPM, the reported } \\
\text { dosimetric concentrations are the } \\
\text { average concentrations or dose per } \\
\text { square area at the bottom of the well. }\end{array}$}} \\
\hline$f_{D}(t)$ & 0.05 & 0.05 & 0.05 & $f_{D}(t)$ & 0.09 & 0.09 & 0.09 & & & & \\
\hline$\mu \mathrm{g} \mathrm{cm}^{-2}$ & 0.77 & 1.55 & 3.88 & $\mu \mathrm{g} \mathrm{cm}^{-2}$ & 0.77 & 1.55 & 3.89 & & & & \\
\hline
\end{tabular}

Figure 1. Cellular response to LCPM derived from polyurethane containing 0.1\% Carbon Nanotubes. A.) Reactive oxygen species generation of LCPM after $24 \mathrm{hr}$ showing a nanofiller effect on ROS levels when comparing PU and PU-CNT LCPM at each dose. B.) Marked decreases in total glutathione in SAEC were observed after exposure to PU-CNT LCPM in comparison to PU. C.) Clear nanofiller effect observed in SAEC exposed to PU-CNT LCPM in comparison to PU only where significant declines in mitochondrial membrane potential and D.) metabolic activity were found. Data represent mean \pm standard deviation for 3 (MTS), 3 (GSH), 3 (TMRE) or 2 (ROS) independent experiments. ${ }^{*}=\mathrm{p}<0.05$ in comparison to media control; $\alpha=\mathrm{P}$-value $<0.01$ (PU vs PU-CNT) (0.06 $\mu \mathrm{g} / \mathrm{cm}^{2}$ ); $\beta=$ P-value $<0.01$ (PU vs PU-CNT) $0.6 \mu \mathrm{g} / \mathrm{cm}^{2} ; \xi=\mathrm{P}$-value $<0.01$ (PU vs PU-CNT) $6.0 \mu \mathrm{g} / \mathrm{cm}^{2}$ $5 \% \mathrm{Fe}_{2} \mathrm{O}_{3}$ in comparison to $\mathrm{PE}$ alone B.) Higher decreases in total glutathione levels were observed in the case of LCPM from PE 5\% $\mathrm{Fe}_{2} \mathrm{O}_{3}$ in comparison to PE alone. C.) No discernible nanofiller effect was observed in mitochondrial function assessments, however PE alone exposures resulted in a dose dependent decrease in membrane potential. D.) At the low and mid doses, a nanofiller effect is evident for 
702

LCPM derived from PE 5\% $\mathrm{Fe}_{2} \mathrm{O}_{3}$ in comparison to PE only. Data represent mean \pm standard deviation for 3 (MTS), 3 (GSH), 3 (TMRE) or 2 (ROS) independent experiments. $*=p<0.05$ in comparison to media control; $\alpha=$ P-value $<0.01$ (PE vs PE-5\% $\mathrm{Fe}_{2} \mathrm{O}_{3}$ ) $0.3 \mu \mathrm{g} / \mathrm{cm}^{2} ; \beta=\mathrm{P}$-value $<0.01$ (PE vs PE-5\% $\left.\mathrm{Fe}_{2} \mathrm{O}_{3}\right) 0.7 \mu \mathrm{g} / \mathrm{cm}^{2} ; \xi=$ P-value $<0.01\left(\mathrm{PE}\right.$ vs PE-5\% $\left.\mathrm{Fe}_{2} \mathrm{O}_{3}\right) 1.5 \mu \mathrm{g} / \mathrm{cm}^{2}$.

Figure 3. Impact of increasing nanofiller loading on LCPM toxicity. A.) A nanofiller effect was found in ROS generation due to EVA LCPM containing $2 \% \mathrm{TiO}_{2}$ and $5 \% \mathrm{TiO}_{2}$ in comparison to EVA only LCPM B.) Significant decreases in total glutathione levels were observed due to EVA and EVA LCPM containing $2 \%$ and $5 \% \mathrm{TiO}_{2}$ C.) Higher decreases in mitochondrial membrane potential was found due to LCPM derived from incinerated $\mathrm{TiO}_{2}$ embedded EVA in contrast to EVA only exposures. D.) Nano-filler mediated reductions in cellular viability were shown after $24 \mathrm{~h}$ exposure to EVA LCPM and EVA only. Data represent mean \pm standard deviation for 3 (MTS), 3 (GSH), 3 (TMRE) or 2 (ROS) independent experiments. $*=\mathrm{p}<0.05$ in comparison to media control; $\alpha=\mathrm{P}$-value $<0.01$ (EVA vs EVA $2 \%$ and 5\% $\left.\mathrm{TiO}_{2}\right)\left(0.8 \mu \mathrm{g} / \mathrm{cm}^{2}\right) ; \beta=\mathrm{P}$-value $<0.01\left(\right.$ EVA vs EVA $2 \%$ and $\left.5 \% \mathrm{TiO}_{2}\right)\left(2.38 \mu \mathrm{g} / \mathrm{cm}^{2}\right) ; \xi=\mathrm{P}$-value $<0.01$ (EVA vs EVA $2 \%$ and $\left.5 \% \mathrm{TiO}_{2}\right)\left(3.18 \mu \mathrm{g} / \mathrm{cm}^{2}\right)$.

Figure 4. Single stranded DNA damage induced by released aerosols from incinerated thermoplastics and related nanocomposites. Single stranded DNA damage produced by A.) PU and PU-CNT B.) PC and PC-CNT (3\% w/v) C.) PE and PE 5\% $\mathrm{Fe}_{2} \mathrm{O}_{3}$ LCPM. Data represents the mean of three individual CometChip assessments, and an average of 700 comets per exposure/dose. ${ }^{*}=\mathrm{p}<0.05$ in comparison to media control; $\xi=$ P-value $<0.01$ (PC vs PC 3\% CNT) $\left(1.9 \mu \mathrm{g} / \mathrm{cm}^{2}\right)$

\section{References}

Al-Saleh, M. H., Gelves, G. A., and Sundararaj, U. (2013). Carbon nanofiber/polyethylene nanocomposite: Processing behavior, microstructure and electrical properties. Materials \& Design 52, 128-133, http://dx.doi.org/10.1016/j.matdes.2013.05.038.

Alarifi, S., Ali, D., Alkahtani, S., and Alhader, M. S. (2014). Iron Oxide Nanoparticles Induce Oxidative Stress, DNA Damage, and Caspase Activation in the Human Breast Cancer Cell Line. Biological Trace Element Research 159(1), 416-424, 10.1007/s12011-014-9972-0.

Bello, D., Martin, J., Santeufemio, C., Sun, Q., Lee Bunker, K., Shafer, M., and Demokritou, P. (2013). Physicochemical and morphological characterisation of nanoparticles from photocopiers: implications for environmental health. Nanotoxicology 7(5), 989-1003, 10.3109/17435390.2012.689883.

Borm, P. J., Robbins, D., Haubold, S., Kuhlbusch, T., Fissan, H., Donaldson, K., Schins, R., Stone, V., Kreyling, W., Lademann, J., Krutmann, J., Warheit, D., and Oberdorster, E. (2006). The potential risks of nanomaterials: a review carried out for ECETOC. Particle and fibre toxicology 3(1), 11, 10.1186/17438977-3-11.

Bouillard, J., R'Mili, B., Moranviller, D., Vignes, A., Le Bihan, O., Ustache, A., Bomfim, J. S., Frejafon, E., and Fleury, D. (2013). Nanosafety by design: risks from nanocomposite/nanowaste combustion. J Nanopart Res 15(4), 1-11, 10.1007/s11051-013-1519-3.

Chen, L., Yokel, R. A., Hennig, B., and Toborek, M. (2008). Manufactured aluminum oxide nanoparticles decrease expression of tight junction proteins in brain vasculature. Journal of neuroimmune pharmacology : the official journal of the Society on Neurolmmune Pharmacology 3(4), 286-95, 10.1007/s11481-008-9131-5. Clarke, M. J., Golden, S. R., Saphire, D., and Kadt, M. d. (1991). Burning garbage in the US: practice vs. state of the art. INFORM, New York, NY. 
Clausen, S. K., Bergqvist, M., Poulsen, L. K., Poulsen, O. M., and Nielsen, G. D. (2003). Development of sensitisation or tolerance following repeated OVA inhalation in BALB/cJ mice. Dose-dependency and modulation by the $\mathrm{Al}(\mathrm{OH}) 3$ adjuvant. Toxicology 184(1), 51-68.

Cohen, J., Deloid, G., Pyrgiotakis, G., and Demokritou, P. (2013). Interactions of engineered nanomaterials in physiological media and implications for in vitro dosimetry. Nanotoxicology 7(4), 41731, 10.3109/17435390.2012.666576.

Cohen, J. M., DeLoid, G. M., and Demokritou, P. (2015). A critical review of in vitro dosimetry for engineered nanomaterials. Nanomedicine (Lond) doi: 10.2217/nnm.15.129, 10.2217/nnm.15.129. Cohen, J. M., Derk, R., Rojanasakul, L., Godleski, J., Kobzik, L., Brain, J., and Demokritou, P. (2014a). Tracking translocation of industrially relevant engineered nanomaterials (ENMs) across alveolar epithelial monolayers in vitro. Nanotoxicology in press, DOI: 10.3109/17435390.2013.879612. Cohen, J. M., Teeguarden, J. G., and Demokritou, P. (2014b). An integrated approach for the in vitro dosimetry of engineered nanomaterials. Particle and fibre toxicology 11(1), 1-12, 10.1186/1743-897711-20.

DeLoid, G., Casella, B., Pirela, S., Filoramo, R., Pyrgiotakis, G., Demokritou, P., and Kobzik, L. (2016). Effects of engineered nanomaterial exposure on macrophage innate immune function. Nanolmpact doi: http://dx.doi.org/10.1016/j.impact.2016.07.001, http://dx.doi.org/10.1016/j.impact.2016.07.001. DeLoid, G., Cohen, J., Darrah, T. H., Pyrgiotakis, G., Wohlleben, W., and Demokritou, P. (2014). Estimating effective density of engineered nanomaterials for in vitro dosimetry. Nature Communications in press.

DeLoid, G. M., Cohen, J. M., Pyrgiotakis, G., Pirela, S. V., Pal, A., Liu, J., Srebric, J., and Demokritou, P. (2015). Advanced computational modeling for in vitro nanomaterial dosimetry. Particle and fibre toxicology 12, 32, 10.1186/s12989-015-0109-1.

Demokritou, P., Lee, S. J., Ferguson, S. T., and Koutrakis, P. (2004). A compact multistage (cascade) impactor for the characterization of atmospheric aerosols. Journal of Aerosol Science 35(3), 281-299, http://dx.doi.org/10.1016/j.jaerosci.2003.09.003.

Di Virgilio, A. L., Reigosa, M., Arnal, P. M., and Fernandez Lorenzo de Mele, M. (2010). Comparative study of the cytotoxic and genotoxic effects of titanium oxide and aluminium oxide nanoparticles in Chinese hamster ovary (CHO-K1) cells. Journal of hazardous materials 177(1-3), 711-8, 10.1016/j.jhazmat.2009.12.089.

Diaz, E., Ordonez, S., and Vega, A. (2007). Adsorption of volatile organic compounds onto carbon nanotubes, carbon nanofibers, and high-surface-area graphites. Journal of colloid and interface science 305(1), 7-16, 10.1016/j.jcis.2006.09.036.

Donaldson, K., Murphy, F., Schinwald, A., Duffin, R., and Poland, C. A. (2010). Identifying the pulmonary hazard of high aspect ratio nanoparticles to enable their safety-by-design. Nanomedicine 6(1), 143-156, 10.2217/nnm.10.139.

Duncan, T. V. (2015). Release of Engineered Nanomaterials from Polymer Nanocomposites: the Effect of Matrix Degradation. ACS Applied Materials \& Interfaces 7(1), 20-39, 10.1021/am5062757. Fang, F. F., Choi, H. J., and Joo, J. (2008). Conducting polymer/clay nanocomposites and their applications. Journal of nanoscience and nanotechnology 8(4), 1559-81. Fatkhutdinova, L. M., Khaliullin, T. O., Vasil'yeva, O. L., Zalyalov, R. R., Mustafin, I. G., Kisin, E. R., Birch, M. E., Yanamala, N., and Shvedova, A. A. (2016). Fibrosis biomarkers in workers exposed to MWCNTs. Toxicology and applied pharmacology 299, 125-31, 10.1016/j.taap.2016.02.016.

Giraldo, L. F., Brostow, W., Devaux, E., López, B. L., and Pérez, L. D. (2008). Scratch and Wear Resistance of Polyamide 6 Reinforced with Multiwall Carbon Nanotubes. Journal of nanoscience and nanotechnology 8(6), 3176-3183, 10.1166/jnn.2008.092.

Grassian, V. H., Haes, A. J., Mudunkotuwa, I. A., Demokritou, P., Kane, A. B., Murphy, C. J., Hutchison, J. E., Isaacs, J. A., Jun, Y.-S., Karn, B., Khondaker, S. I., Larsen, S. C., Lau, B. L. T., Pettibone, J. M., Sadik, O. 
A., Saleh, N. B., and Teague, C. (2016). NanoEHS - defining fundamental science needs: no easy feat when the simple itself is complex. Environmental Science: Nano 3(1), 15-27, 10.1039/C5EN00112A. Gui, W., Wisnewski, A. V., Neamtiu, I., Gurzau, E., Sparer, J. A., Stowe, M. H., Liu, J., Slade, M. D., Rusu, O. A., and Redlich, C. A. (2014). Inception Cohort Study of Workers Exposed to Toluene Diisocyanate at a Polyurethane Foam Factory: Initial One-Year Follow-up. American journal of industrial medicine 57(11), 1207-1215, 10.1002/ajim.22385.

Herner, J. D., Green, P. G., and Kleeman, M. J. (2006). Measuring the trace elemental composition of size-resolved airborne particles. Environmental science \& technology 40(6), 1925-33.

Hirth, S., Cena, L., Cox, G., Tomović, Ž., Peters, T., and Wohlleben, W. (2013). Scenarios and methods that induce protruding or released CNTs after degradation of nanocomposite materials. J Nanopart Res 15(4), 1-15, 10.1007/s11051-013-1504-x. Huang, Y. Y., and Terentjev, E. M. (2010). Tailoring the Electrical Properties of Carbon NanotubePolymer Composites. Advanced Functional Materials 20(23), 4062-4068, 10.1002/adfm.201000861. Keller, A. A., and Lazareva, A. (2014). Predicted Releases of Engineered Nanomaterials: From Global to Regional to Local. Environmental Science \& Technology Letters 1(1), 65-70, 10.1021/ez400106t. Kitahara, Y., Takahashi, S., Tsukagoshi, M., and Fujii, T. (2010). Formation of bisphenol A by thermal degradation of poly(bisphenol A carbonate). Chemosphere 80(11), 1281-4, 10.1016/j.chemosphere.2010.06.053.

Konduru, N. V., Murdaugh, K. M., Sotiriou, G. A., Donaghey, T. C., Demokritou, P., Brain, J. D., and Molina, R. M. (2014). Bioavailability, distribution and clearance of tracheally-instilled and gavaged uncoated or silica-coated zinc oxide nanoparticles. Particle and fibre toxicology 11, 44, 10.1186/s12989014-0044-6.

Larsen, S. T., Jackson, P., Poulsen, S. S., Levin, M., Jensen, K. A., Wallin, H., Nielsen, G. D., and Koponen, I. K. (2016). Airway irritation, inflammation and toxicity in mice following inhalation of metal oxide nanoparticles. Nanotoxicology doi: 10.1080/17435390.2016.1202350, 1-36, 10.1080/17435390.2016.1202350.

Li, S., Meng Lin, M., Toprak, M. S., Kim, D. K., and Muhammed, M. (2010). Nanocomposites of polymer and inorganic nanoparticles for optical and magnetic applications. Nano Reviews 1, 10.3402/nano.v1i0.5214, 10.3402/nano.v1i0.5214.

Lu, X., Miousse, I. R., Pirela, S. V., Melnyk, S., Koturbash, I., and Demokritou, P. (2016a). Short-term exposure to engineered nanomaterials affects cellular epigenome. Nanotoxicology 10(2), 140-50, 10.3109/17435390.2015.1025115.

Lu, X., Miousse, I. R., Pirela, S. V., Moore, J. K., Melnyk, S., Koturbash, I., and Demokritou, P. (2016b). In vivo epigenetic effects induced by engineered nanomaterials: A case study of copper oxide and laser printer-emitted engineered nanoparticles. Nanotoxicology 10(5), 629-39, 10.3109/17435390.2015.1108473.

Meyer, R. A., and Green, J. J. (2015). Biodegradable polymer iron oxide nanocomposites: the future of biocompatible magnetism. Nanomedicine (Lond) 10(23), 3421-3425, 10.2217/nnm.15.165. Mihalchik, A. L., Ding, W., Porter, D. W., McLoughlin, C., Schwegler-Berry, D., Sisler, J. D., Stefaniak, A. B., Snyder-Talkington, B. N., Cruz-Silva, R., Terrones, M., Tsuruoka, S., Endo, M., Castranova, V., and Qian, Y. (2015). Effects of nitrogen-doped multi-walled carbon nanotubes compared to pristine multi-walled carbon nanotubes on human small airway epithelial cells. Toxicology 333, 25-36, 10.1016/j.tox.2015.03.008. Mu, Y., Wu, F., Zhao, Q., Ji, R., Qie, Y., Zhou, Y., Hu, Y., Pang, C., Hristozov, D., Giesy, J. P., and Xing, B. (2016). Predicting Toxic Potencies of Metal Oxide Nanoparticles by Means of Nano-QSARs. Nanotoxicology doi: 10.1080/17435390.2016.1202352, 1-25, 10.1080/17435390.2016.1202352. 
Nel, A., Xia, T., Meng, H., Wang, X., Lin, S., Ji, Z., and Zhang, H. (2013). Nanomaterial toxicity testing in the 21st century: use of a predictive toxicological approach and high-throughput screening. Accounts of chemical research 46(3), 607-21, 10.1021/ar300022h.

Novakova, A. A., Lanchinskaya, V. Y., Volkov, A. V., Gendler, T. S., Kiseleva, T. Y., Moskvina, M. A., and Zezin, S. B. (2003). Magnetic properties of polymer nanocomposites containing iron oxide nanoparticles. Journal of Magnetism and Magnetic Materials 258-259, 354-357, http://dx.doi.org/10.1016/S03048853(02)01062-4.

Pal, A. K., Bello, D., Cohen, J., and Demokritou, P. (2015a). Implications of in vitro dosimetry on toxicological ranking of low aspect ratio engineered nanomaterials. Nanotoxicology 9(7), 871-85, 10.3109/17435390.2014.986670.

Pal, A. K., Watson, C. Y., Pirela, S. V., Singh, D., Chalbot, M. C., Kavouras, I., and Demokritou, P. (2015b). Linking Exposures of Particles Released From Nano-Enabled Products to Toxicology: An Integrated Methodology for Particle Sampling, Extraction, Dispersion, and Dosing. Toxicological sciences : an official journal of the Society of Toxicology 146(2), 321-33, 10.1093/toxsci/kfv095. Palza, H. (2015). Antimicrobial polymers with metal nanoparticles. International journal of molecular sciences 16(1), 2099-116, 10.3390/ijms16012099.

Pan, B., and Xing, B. (2008). Adsorption mechanisms of organic chemicals on carbon nanotubes. Environmental science \& technology 42(24), 9005-13.

Panwar, H., Jain, D., Khan, S., Pathak, N., Raghuram, G. V., Bhargava, A., Banerjee, S., and Mishra, P. K. (2013). Imbalance of mitochondrial-nuclear cross talk in isocyanate mediated pulmonary endothelial cell dysfunction. Redox biology 1, 163-71, 10.1016/j.redox.2013.01.009.

Pavanello, S., Dioni, L., Hoxha, M., Fedeli, U., Mielzynska-Svach, D., and Baccarelli, A. A. (2013). Mitochondrial DNA copy number and exposure to polycyclic aromatic hydrocarbons. Cancer epidemiology, biomarkers \& prevention : a publication of the American Association for Cancer Research, cosponsored by the American Society of Preventive Oncology 22(10), 1722-9, 10.1158/1055-9965.epi-130118.

Perkgoz, N. K., Toru, R. S., Unal, E., Sefunc, M. A., Tek, S., Mutlugun, E., Soganci, I. M., Celiker, H., Celiker, G., and Demir, H. V. (2011). Photocatalytic hybrid nanocomposites of metal oxide nanoparticles enhanced towards the visible spectral range. Applied Catalysis B: Environmental 105(1-2), 77-85, http://dx.doi.org/10.1016/i.apcatb.2011.03.037. Pirela, S., Molina, R., Watson, C., Cohen, J. M., Bello, D., Demokritou, P., and Brain, J. (2013). Effects of copy center particles on the lungs: a toxicological characterization using a Balb/c mouse model. Inhalation toxicology 25(9), 498-508, 10.3109/08958378.2013.806614.

Pirela, S. V., Lu, X., Miousse, I., Sisler, J. D., Qian, Y., Guo, N., Koturbash, I., Castranova, V., Thomas, T., Godleski, J., and Demokritou, P. (2016). Effects of intratracheally instilled laser printer-emitted engineered nanoparticles in a mouse model: A case study of toxicological implications from nanomaterials released during consumer use. Nanolmpact 1, 1-8, http://dx.doi.org/10.1016/i.impact.2015.12.001.

Pirela, S. V., Pyrgiotakis, G., Bello, D., Thomas, T., Castranova, V., and Demokritou, P. (2014a). Development and characterization of an exposure platform suitable for physico-chemical, morphological and toxicological characterization of printer-emitted particles (PEPs). Inhalation toxicology 26(7), 400-8, 10.3109/08958378.2014.908987.

Pirela, S. V., Sotiriou, G. A., Bello, D., Shafer, M., Bunker, K. L., Castranova, V., Thomas, T., and Demokritou, P. (2014b). Consumer exposures to laser printer-emitted engineered nanoparticles: A case study of life-cycle implications from nano-enabled products. Nanotoxicology doi: 10.3109/17435390.2014.976602, 1-9, 10.3109/17435390.2014.976602. 
Sahoo, N. G., Rana, S., Cho, J. W., Li, L., and Chan, S. H. (2010). Polymer nanocomposites based on functionalized carbon nanotubes. Progress in Polymer Science 35(7), 837-867, http://dx.doi.org/10.1016/i.progpolymsci.2010.03.002. Saquib, Q., Al-Khedhairy, A. A., Siddiqui, M. A., Abou-Tarboush, F. M., Azam, A., and Musarrat, J. (2012). Titanium dioxide nanoparticles induced cytotoxicity, oxidative stress and DNA damage in human amnion epithelial (WISH) cells. Toxicology in vitro : an international journal published in association with BIBRA 26(2), 351-61, 10.1016/j.tiv.2011.12.011.

Schauer, J. J., Mader, B. T., Deminter, J. T., Heidemann, G., Bae, M. S., Seinfeld, J. H., Flagan, R. C., Cary, R. A., Smith, D., Huebert, B. J., Bertram, T., Howell, S., Kline, J. T., Quinn, P., Bates, T., Turpin, B., Lim, H. J., Yu, J. Z., Yang, H., and Keywood, M. D. (2003). ACE-Asia intercomparison of a thermal-optical method for the determination of particle-phase organic and elemental carbon. Environmental science \& technology 37(5), 993-1001.

Shukla, R. K., Sharma, V., Pandey, A. K., Singh, S., Sultana, S., and Dhawan, A. (2011). ROS-mediated genotoxicity induced by titanium dioxide nanoparticles in human epidermal cells. Toxicology in vitro : an international journal published in association with BIBRA 25(1), 231-41, 10.1016/j.tiv.2010.11.008. Sisler, J. D., Pirela, S. V., Friend, S., Farcas, M., Schwegler-Berry, D., Shvedova, A., Castranova, V., Demokritou, P., and Qian, Y. (2014). Small airway epithelial cells exposure to printer-emitted engineered nanoparticles induces cellular effects on human microvascular endothelial cells in an alveolar-capillary co-culture model. Nanotoxicology 0(0), 1-11, 10.3109/17435390.2014.976603.

Sotiriou, G. A., Singh, D., Zhang, F., Chalbot, M. C., Spielman-Sun, E., Hoering, L., Kavouras, I. G., Lowry, G. V., Wohlleben, W., and Demokritou, P. (2016). Thermal decomposition of nano-enabled thermoplastics: Possible environmental health and safety implications. Journal of hazardous materials 305, 87-95, 10.1016/j.jhazmat.2015.11.001.

Sotiriou, G. A., Singh, D., Zhang, F., Wohlleben, W., Chalbot, M.-C. G., Kavouras, I. G., and Demokritou, P. (2015). An integrated methodology for the assessment of environmental health implications during thermal decomposition of nano-enabled products. Environmental science. Nano 2(3), 262-272, 10.1039/C4ENO0210E.

Sotiriou, G. A., Watson, C., Murdaugh, K. M., Darrah, T. H., Pyrgiotakis, G., Elder, A., Brain, J. D., and Demokritou, P. (2014). Engineering safer-by-design, transparent, silica-coated ZnO nanorods with reduced DNA damage potential. Environmental Science: Nano in press, DOI: 10.1039/C3EN00062A. Srivastava, R. K., Rahman, Q., Kashyap, M. P., Singh, A. K., Jain, G., Jahan, S., Lohani, M., Lantow, M., and Pant, A. B. (2013). Nano-titanium dioxide induces genotoxicity and apoptosis in human lung cancer cell line, A549. Human \& experimental toxicology 32(2), 153-66, 10.1177/0960327112462725. Stojanović, D. B., Brajović, L., Orlović, A., Dramlić, D., Radmilović, V., Uskoković, P. S., and Aleksić, R. (2013). Transparent PMMA/silica nanocomposites containing silica nanoparticles coating under supercritical conditions. Progress in Organic Coatings 76(4), 626-631, http://dx.doi.org/10.1016/j.porgcoat.2012.12.002.

Teuten, E. L., Saquing, J. M., Knappe, D. R. U., Barlaz, M. A., Jonsson, S., Björn, A., Rowland, S. J., Thompson, R. C., Galloway, T. S., Yamashita, R., Ochi, D., Watanuki, Y., Moore, C., Viet, P. H., Tana, T. S., Prudente, M., Boonyatumanond, R., Zakaria, M. P., Akkhavong, K., Ogata, Y., Hirai, H., Iwasa, S., Mizukawa, K., Hagino, Y., Imamura, A., Saha, M., and Takada, H. (2009). Transport and release of chemicals from plastics to the environment and to wildlife. Philosophical Transactions of the Royal Society of London B: Biological Sciences 364(1526), 2027-2045, 10.1098/rstb.2008.0284. Tsuruoka, S., Matsumoto, H., Castranova, V., Porter, D. W., Yanagisawa, T., Saito, N., Kobayashi, S., and Endo, M. (2015). Differentiation of chemical reaction activity of various carbon nanotubes using redox potential: Classification by physical and chemical structures. Carbon 95, 302-308. 
Vales, G., Rubio, L., and Marcos, R. (2016). Genotoxic and cell-transformation effects of multi-walled carbon nanotubes (MWCNT) following in vitro sub-chronic exposures. Journal of hazardous materials 306, 193-202, 10.1016/j.jhazmat.2015.12.021.

Vejerano, E. P., Leon, E. C., Holder, A. L., and Marr, L. C. (2014). Characterization of particle emissions and fate of nanomaterials during incineration. Environmental Science: Nano 1(2), 133-143, 10.1039/C3EN00080J.

Wang, L., Luanpitpong, S., Castranova, V., Tse, W., Lu, Y., Pongrakhananon, V., and Rojanasakul, Y. (2011). Carbon nanotubes induce malignant transformation and tumorigenesis of human lung epithelial cells. Nano letters 11(7), 2796-803, 10.1021/nl2011214.

Wang, W., Ciselli, P., Kuznetsov, E., Peijs, T., and Barber, A. H. (2008). Effective reinforcement in carbon nanotube-polymer composites. Philosophical Transactions of the Royal Society of London A:

Mathematical, Physical and Engineering Sciences 366(1870), 1613-1626, 10.1098/rsta.2007.2175. Wang, Z., Wang, J., Richter, H., Howard, J. B., Carlson, J., and Levendis, Y. A. (2003). Comparative Study on Polycyclic Aromatic Hydrocarbons, Light Hydrocarbons, Carbon Monoxide, and Particulate Emissions from the Combustion of Polyethylene, Polystyrene, and Poly(vinyl chloride). Energy \& Fuels 17(4), 9991013, 10.1021/ef020269z.

Watson, C. Y., DeLoid, G. M., Pal, A., and Demokritou, P. (2016). Buoyant Nanoparticles: Implications for Nano-Biointeractions in Cellular Studies. Small 12(23), 3172-80, 10.1002/smll.201600314.

Watson, C. Y., Ge, J., Cohen, J., Pyrgiotakis, G., Engelward, B., and Demokritou, P. (2013). HighThroughput Screening Platform for Engineered Nanoparticle-Mediated Genotoxicity Using CometChip Technology. ACS Nano 8(3), 2118-2133, 10.1021/nn404871p.

Watson, C. Y., Molina, R. M., Louzada, A., Murdaugh, K. M., Donaghey, T. C., and Brain, J. D. (2015). Effects of zinc oxide nanoparticles on Kupffer cell phagosomal motility, bacterial clearance, and liver function. International journal of nanomedicine 10, 4173-84, 10.2147/ijn.s82807.

Wohlleben, W., Brill, S., Meier, M. W., Mertler, M., Cox, G., Hirth, S., von Vacano, B., Strauss, V., Treumann, S., Wiench, K., Ma-Hock, L., and Landsiedel, R. (2011). On the lifecycle of nanocomposites: comparing released fragments and their in-vivo hazards from three release mechanisms and four nanocomposites. Small 7(16), 2384-95, 10.1002/smll.201002054.

Wohlleben, W., and Neubauer, N. (2016). Quantitative rates of release from weathered nanocomposites are determined across 5 orders of magnitude by the matrix, modulated by the embedded nanomaterial. Nanolmpact 1, 39-45, http://dx.doi.org/10.1016/i.impact.2016.01.001. 
A.

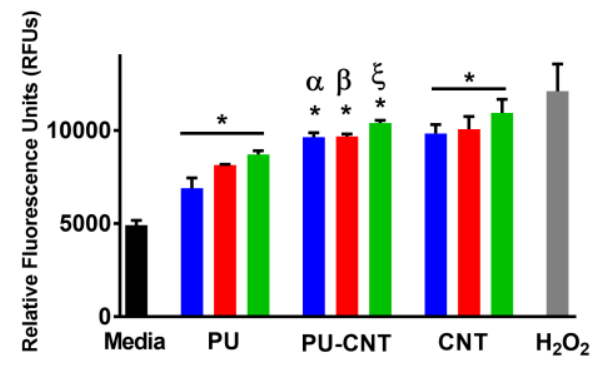

C.

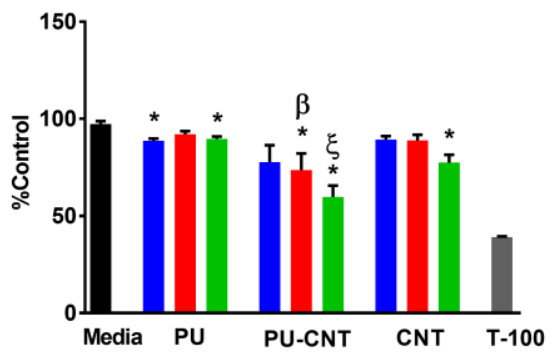

B.

Delivered Dose

- $0.06 \mu \mathrm{g} / \mathrm{cm}^{2}$

- $0.6 \mu \mathrm{g} / \mathrm{cm}^{2}$

Delivered Dose

- $0.06 \mu \mathrm{g} / \mathrm{cm}^{2}$

$0.6 \mu \mathrm{g} / \mathrm{cm}^{2}$

- $6.0 \mu \mathrm{g} / \mathrm{cm}^{2}$

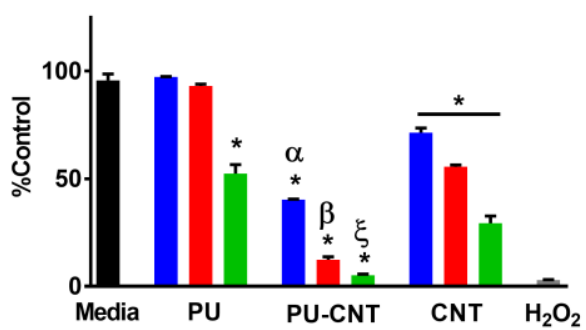

D.

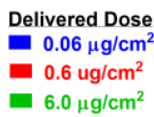

6.0

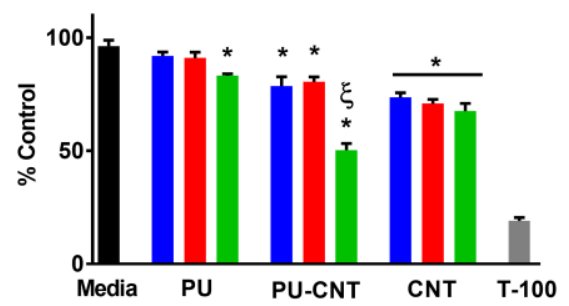


A.

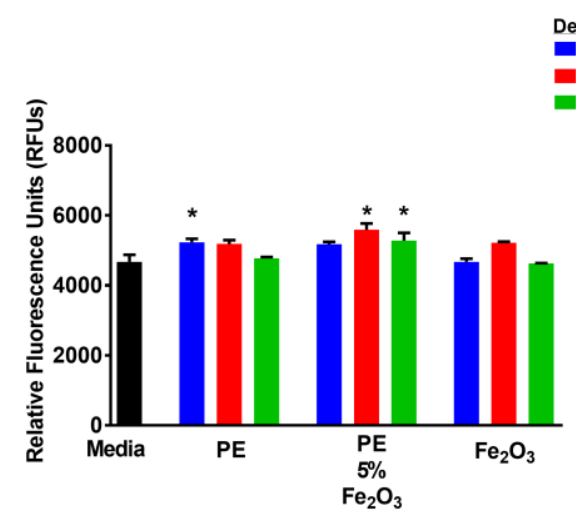

C.

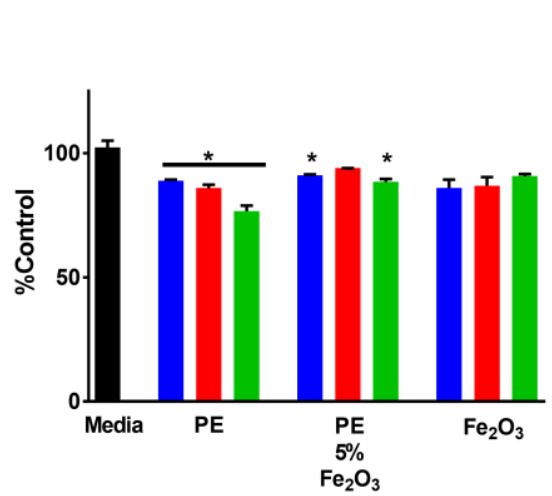

B.

Delivered Dose

a $0.3 \mu \mathrm{g} / \mathrm{cm}^{2}$

- $0.7 \mu \mathrm{g} / \mathrm{cm}^{2}$

- $1.5 \mu \mathrm{g} / \mathrm{cm}^{2}$

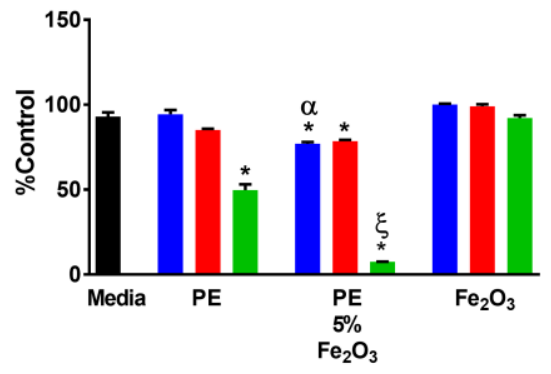

D.

Delivered Dose

- $0.3 \mu \mathrm{g} / \mathrm{cm}^{2}$

- $0.7 \mu \mathrm{g} / \mathrm{cm}^{2}$

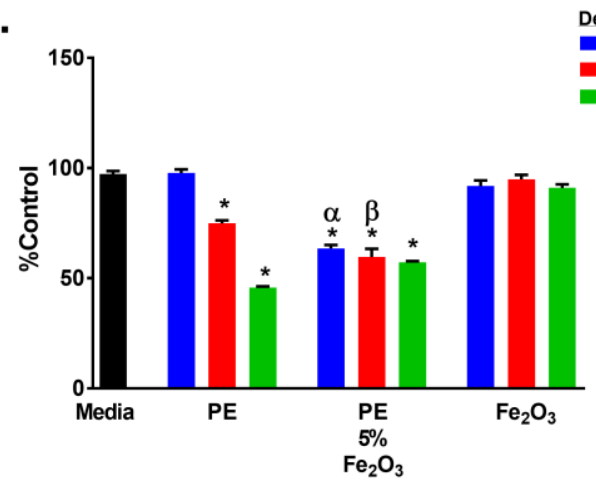


A.

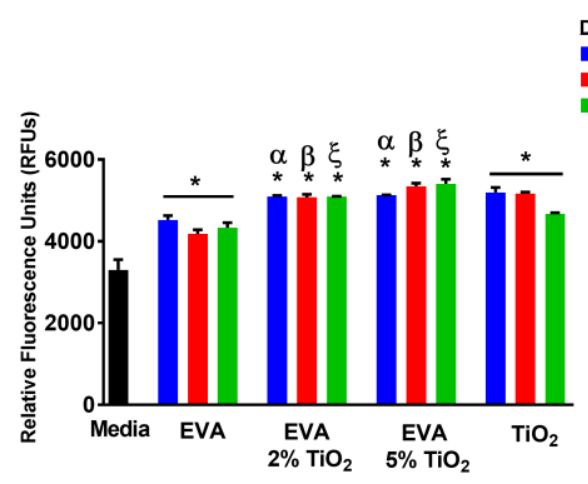

C.

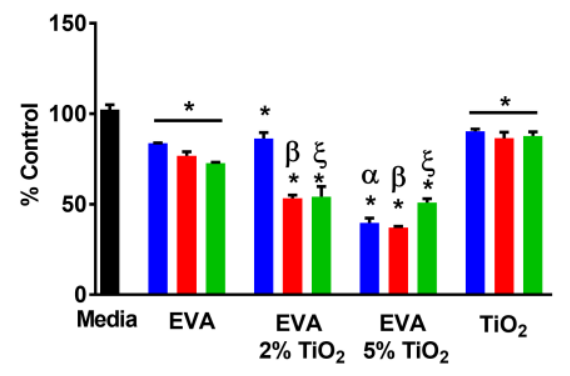

B.

Delivered Dose

- $0.79 \mu \mathrm{g} / \mathrm{cm}^{2}$

- $2.38 \mu \mathrm{g} / \mathrm{cm}^{2}$

Delivered Dose

$0.79 \mu \mathrm{g} / \mathrm{cm}^{2}$

- $2.38 \mu \mathrm{g} / \mathrm{cm}^{2}$

D.

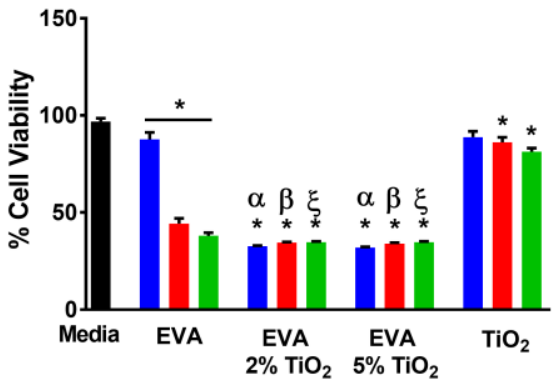

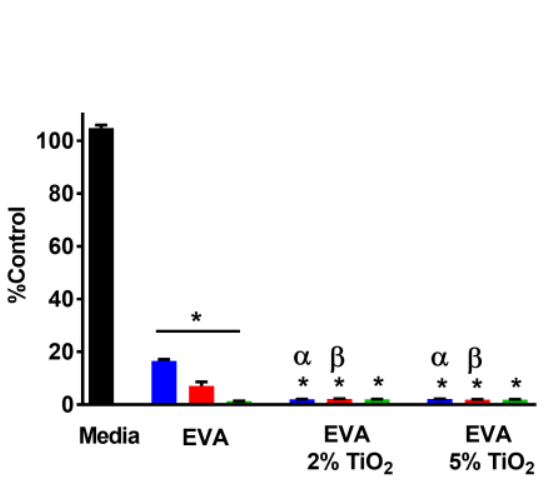

ivered Dose

- $0.79 \mu \mathrm{g} / \mathrm{cm}^{2}$

- $2.38 \mu \mathrm{g} / \mathrm{cm}^{2}$

- $3.13 \mu \mathrm{g} / \mathrm{cm}^{2}$ 


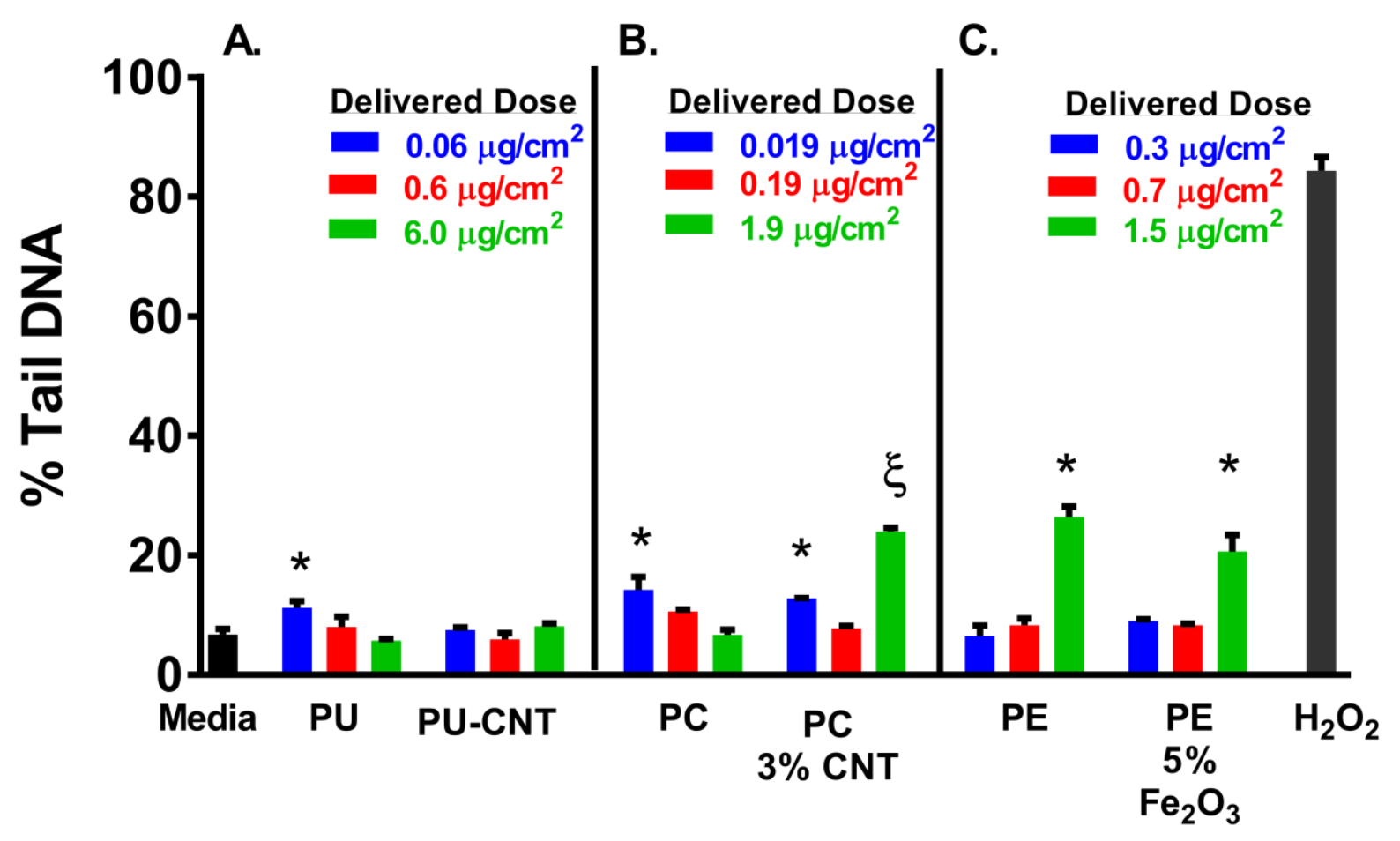

